\title{
High Efficiency Microwave Absorption Performance of Cobalt Ferrite Microspheres/multi-walled Carbon Nanotube Composites
}

Hongmei Liu

Huaibei Normal University

Min Zhang ( $\nabla$ zmin@mail.ustc.edu.cn )

Huaibei Normal University https://orcid.org/0000-0001-9287-1919

Kang Hu

Huaibei Normal University

Xiangkai Kong

Huaibei Normal University

Qiang Li

Huaibei Normal University

Qiangchun Liu

Huaibei Normal University

\section{Research Article}

Keywords: Spinel ferrite, solvothermal method, composites, microwave absorption

Posted Date: February 11th, 2021

DOI: https://doi.org/10.21203/rs.3.rs-159147/v1

License: () (1) This work is licensed under a Creative Commons Attribution 4.0 International License.

Read Full License

Version of Record: A version of this preprint was published at Journal of Materials Science: Materials in Electronics on April 13th, 2021. See the published version at https://doi.org/10.1007/s10854-021-058778. 


\section{High efficiency microwave absorption performance of cobalt ferrite microspheres/multi-walled carbon nanotube composites}

Hongmei Liu, Min Zhang*, Kang Hu, Xiangkai Kong, Qiang Li, Qiangchun Liu* Anhui Province Key Laboratory of Pollutant Sensitive Materials and Environmental Remediation, School of Physics and Electronic Information, Huaibei Normal University, Huaibei 235000, People's Republic of China

\section{ABSTRACT}

In this article, spinel ferrite $\mathrm{CoFe}_{2} \mathrm{O}_{4}$ and multi-walled carbon nanotubes (MWCNTs) composites are constructed by a facile one-step solvothermal method. The pure phase of $\mathrm{CoFe}_{2} \mathrm{O}_{4}$ particles is confirmed by X-ray diffraction patterns. Microstructure analysis demonstrates that monodisperse $\mathrm{CoFe}_{2} \mathrm{O}_{4}$ microspheres are wound by MWCNTs. By the introduction of CNTs, there is a significant enhancement in the imaginary part of permittivity $\left(\varepsilon^{\prime \prime}\right)$ with the composites. The champion microwave absorption performance can be achieved in the composites by the balance of complex permittivity and permeability. When the mass fraction of CNTs is $3 \%$, a minimum reflection loss $\left(\mathrm{RL}_{\mathrm{min}}\right)$ of the composites is as high as $-46.65 \mathrm{~dB}$ at 14.4 $\mathrm{GHz}$ at a thin thickness of $1.5 \mathrm{~mm}$, and the corresponding effective absorption bandwidth below $-10 \mathrm{~dB}$ reaches $4.91 \mathrm{GHz}$ ranging from 12.41 to $17.32 \mathrm{GHz}$ which covers almost the whole Ku band (12.0-18.0 GHz). In other words, this as-synthesized composites show the most outstanding specific $R L_{\text {min }}$ of $-31.1 \mathrm{~dB} \cdot \mathrm{mm}^{-1}$. Such superior microwave absorption behaviors of $\mathrm{CoFe}_{2} \mathrm{O}_{4} / \mathrm{CNTs}$ originate mainly from multiple dielectric relaxation processes, enhanced impedance matching and magnetic loss, as well as the considerable interface between mesoporous $\mathrm{CoFe}_{2} \mathrm{O}_{4}$ hollow microspheres and CNTs, and thereby promoting microwave reflection and scattering within the samples. Our results indicate that as-fabricated $\mathrm{CoFe}_{2} \mathrm{O}_{4} / \mathrm{CNTs}$ composites can be a promising microwave absorbent integrating with thin thickness, strong absorption ability, and broad bandwidth absorption.

Keywords: Spinel ferrite; solvothermal method; composites; microwave absorption;

*) Author to whom correspondence should be addressed:

Electronic mail: zmin@mail.ustc.edu.cn (M. Zhang); qchliu@chnu.edu.cn (Q.C. Liu) 


\section{Introduction}

With the widespread use of electronic devices and wireless communication, electromagnetic interference has become a serious problem in polluting the communication environment and harming human health [1-3]. To tackle the adverse problems we are facing, high-performance microwave absorbers are urgently demanded, which can convert most of the electromagnetic energy onto the surface into thermal or other forms of energy $[4,5]$. By and large, high-efficiency microwave absorbers are required to fulfill the four characteristics of wide bandwidth, strong absorption, low thickness as well as light mass. If applied in the field of high temperature, it often also needs to possess the high-temperature stability. As we now know, the champion microwave absorption properties of materials are highly associated with two aspects of impedance matching and attenuation characteristics, which can actually be achieved through modulating the electromagnetic parameters of the absorbers.

Over the past several decades, enormous efforts have been devoted to the investigation of several magnetic absorbers with high magnetic loss, especial for transition metal oxides. Among these transition metal oxides, the spinel ferrite of $\mathrm{CoFe}_{2} \mathrm{O}_{4}$ has been extensively carried out as microwave absorbers in terms of its moderate saturation magnetization, strong anisotropy, high chemical stability, excellent oxidation resistance and corrosion resistance, as well as low cost [6-9]. Nevertheless, as the microwave absorbers, the disadvantage is that the specific gravity and narrow frequency bandwidth along with bulk $\mathrm{CoFe}_{2} \mathrm{O}_{4}$ always limit its actual application. As previously reported [10-12], a large amount of research work has been done to optimize microwave absorption performances by regulating the morphology of $\mathrm{CoFe}_{2} \mathrm{O}_{4}$ to fiber, rugby, particle or some other shapes, whereas we found that it is extremely difficult to achieve outstanding microwave absorption performances using only $\mathrm{CoFe}_{2} \mathrm{O}_{4}$ as a sole component material. In contrast, it is noteworthy that the most researchers tend to pay close attention to such composites composed of $\mathrm{CoFe}_{2} \mathrm{O}_{4}$-based magnetic/dielectric materials, like carbon materials, $\mathrm{MoS}_{2}, \mathrm{BaTiO}_{3}$ and so on, rather than bulk $\mathrm{CoFe}_{2} \mathrm{O}_{4}$ alone $[6-8,13-15]$. As the representative 
dielectric absorbers, carbon materials with high dielectric loss have attracted growing attention in terms of its high electric conductivity, considerable specific surface and low density. Unfortunately, since the real and imaginary parts of complex permittivity of carbon materials are too large to match with the impedance of free space owing to the pretty strong conductivity and low magnetic loss, arousing electromagnetic waves cannot enter into the absorber interior effectively and reflect on its surface, ultimately weakening the microwave absorption performance. Therefore, it is absolutely essential to incorporate magnetic materials into the carbon materials to balance the real and imaginary parts of the complex permittivity and permeability, and optimize their impedance matching and meanwhile improve the attenuation ability. In light of this, considerable investigations have been carried out to fill carbon materials into $\mathrm{CoFe}_{2} \mathrm{O}_{4}$ magnetic particles. For instance, Wang and co-workers have obtained the $\mathrm{CoFe}_{2} \mathrm{O}_{4} @$ graphene by a spray drying method. The flower-like structure endows it outstanding microwave absorption characteristics with a minimum reflection loss (RLmin) of $-42 \mathrm{~dB}$ at $12.9 \mathrm{GHz}$ with a layer thickness of $2 \mathrm{~mm}$, and the corresponding effective absorption frequency less than $-10 \mathrm{~dB}$ of $4.59 \mathrm{GHz}$ [6]. A previous study reported that $\mathrm{CoFe}_{2} \mathrm{O}_{4}$ could be filled into porous $\mathrm{C}$, in which carbon material is obtained origin from the eggshell membrane [8]. The enhancement of microwave absorption properties is ascribed to the strong synergetic effect between $\mathrm{CoFe}_{2} \mathrm{O}_{4}$ with high magnetic loss and porous carbon with large dielectric loss. Zhang et al. have constructed $\mathrm{CoFe}_{2} \mathrm{O}_{4} / \mathrm{CNTs}$ composites with core/shell structure as absorbers, from which the $\mathrm{RL}_{\min }$ is $-32.8 \mathrm{~dB}$ at $11.7 \mathrm{GHz}$ with $2 \mathrm{~mm}$ [16]. However, so far as we know, $\mathrm{CoFe}_{2} \mathrm{O}_{4}$-based composites still cannot achieve remarkable reflection loss values under a relatively thin thickness, namely large specific $\mathrm{RL}_{\text {min, }}$ as wide bandwidth as possible because of their limited dielectric loss factor.

Inspired by these thoughts mentioned above, and meanwhile considering carbon nanotubes with unique structure, light weight and large dielectric loss, in this work the composites of $\mathrm{CoFe}_{2} \mathrm{O}_{4} / \mathrm{MWCNTs}$ with different loading ratios of CNTs were fabricated through a facile solvothermal method. The effect of the loading concentration of CNTs on microstructure, electromagnetic parameters and microwave 
absorption properties of the composites was investigated systematically. The probable mechanism of the enhancing microwave absorption performance of the composite was discussed in detail.

\section{Experimental section}

\subsection{Synthesis of $\mathrm{CoFe}_{2} \mathrm{O}_{4} / \mathrm{MWCNTs}$ composites}

The composites of $\mathrm{CoFe}_{2} \mathrm{O}_{4} /$ multi-walled carbon nanotubes (CFO/MWCNTs) with various loading ratios of CNTs were prepared by one-pot solvothermal method. All starting materials are of analytical grade and used without further purification. The detailed preparation process of involved composites is as follows. The MWCNTs of $10-20 \mathrm{~nm}$ in diameter and $10-30 \mu \mathrm{m}$ in length were functionalized with $-\mathrm{COOH}$ and $-\mathrm{OH}$ in a Teflon-lined autoclave by the acidified treatment. In a typical synthesis, $0.2 \mathrm{~g}$ MWCNTs were added to $15 \mathrm{ml}$ water and $15 \mathrm{ml}$ nitric acid treated by ultrasonic for 60 minutes. Next, the mixture solution was transferred into a $50 \mathrm{ml}$ white Teflon-lined autoclave, and placed in a drying oven at $120{ }^{\circ} \mathrm{C}$ for 10 hours. After cooled down the room temperature, the acidified MWCNTs were washed repeatedly for several times by deionized water and ethanol, and then freeze-dried overnight to obtain fluffy MWCNTs powders. To fabricate the composites, a certain amount of pre-treated and activated MWCNTs powders was first dispersed into $35 \mathrm{ml}$ ethylene glycol (EG). After ultrasonic treatment for 40 minutes, a homogeneous solution was produced. Subsequently, $0.6008 \mathrm{~g} \mathrm{CoCl}_{2} \cdot 6 \mathrm{H}_{2} \mathrm{O}$ and $1.3652 \mathrm{~g} \mathrm{FeCl}_{3} \cdot 6 \mathrm{H}_{2} \mathrm{O}$ were dissolved in the above mixture to form a homogeneous solution by ultrasonically treated for 1 hour. Afterwards, $2.73 \mathrm{~g}$ urea and $1.0 \mathrm{~g}$ polyethylene glycol-20000 were added. After being magnetically stirred for another 1 hour, the as-prepared precursor solution was transferred into a $50 \mathrm{ml}$ Teflon-lined autoclave and kept at $200{ }^{\circ} \mathrm{C}$ for 24 hours. When the autoclave was naturally cooled to room temperature, the products were magnetically separated and cleaned several times with deionized water and anhydrous ethanol, and finally dried in a vacuum drying oven at $60{ }^{\circ} \mathrm{C}$ for 24 hours. For convenience, with various mass fraction of MWCNTs $(0,1 \%, 3 \%, 5 \%)$, the resulting products were named as $\mathrm{CFO}, \mathrm{CFO} / 1 \% \mathrm{CNTs}, \mathrm{CFO} / 3 \% \mathrm{CNTs}$ and $\mathrm{CFO} / 5 \%$ CNTs, respectively. 


\subsection{Characterization}

The phase analysis of all as-prepared samples was characterized by powder $\mathrm{X}$-ray diffraction $(\mathrm{XRD})$ of $\mathrm{Cu} \mathrm{K} \alpha$ radiation source. The microstructure of as-obtained materials was examined by field emission scanning electron microscopy (FESEM, SU8220) and transmission electron microscope (TEM, JEOL JEM-2100). $\mathrm{N}_{2}$ adsorption-desorption isotherm and Barrett-Joyner-Halenda (BJH) methods were conducted on a Micromeritics ASAP 2460 analyzer at $77 \mathrm{~K}$. The vector network analyzer (VNA, AV3629D) was carried out to record the room-temperature electromagnetic parameters of samples in the measured frequency range of 2.0-18.0 $\mathrm{GHz}$, where the composites were uniformly mixed with $50 \mathrm{wt} \%$ paraffin, and then compressed into a cylindrical toroid with an inner diameter of $3.04 \mathrm{~mm}$, an outer diameter of $7.00 \mathrm{~mm}$ and a thickness of $2.00 \mathrm{~mm}$. In order to reduce or eliminate the errors caused by source matching, load matching, directivity, isolation and frequency response in microwave measurement, the full dual port calibration was carried out before measurement, and the reflection loss of samples was simulated by the transmission line theory.

\section{Results and discussion}

The crystalline phase of as-prepared $\mathrm{CoFe}_{2} \mathrm{O}_{4}, \mathrm{CoFe}_{2} \mathrm{O}_{4} / \mathrm{CNTs}$ and acid-treated MWCNTs samples is examined by XRD patterns, as shown in Fig. 1. Here, these six peaks located at $30.1^{\circ}, 35.4^{\circ}, 43.1^{\circ}, 53.4^{\circ}, 56.9^{\circ}$ and $62.4^{\circ}$ corresponds to crystal planes of (220), (311), (400), (422), (511) and (440) of spinel $\mathrm{CoFe}_{2} \mathrm{O}_{4}$ ferrite with standard JCPDS card number 22-1086, respectively, confirming the high purity of CFO phase in the composites. The obvious diffraction peak appears at $2 \theta=25.9$ along with the acid-treated MWCNTs samples, corresponding to the crystal plane of (002) of CNTs. Nevertheless, this mentioned diffraction peak of CNTs is not detected in these composites, which may be due to the low content of CNTs, and the similar results have also been reported in composites of $\mathrm{MWCNTs} / \mathrm{ZnFe}_{2} \mathrm{O}_{4}$ and MWCNTs/ $\mathrm{BaFe}_{12} \mathrm{O}_{19} @ \mathrm{ZnFe}_{2} \mathrm{O}_{4}$ [17].

Figure 2 exhibits the surface morphology and microstructure of CFO/CNTs with different loading ratios of CNTs. As can be seen from Fig. 2a, the pure CFO sample is 
composed of monodisperse microspheres with uniform size of 200-300 nm. By observing some magnified CFO spheres, it is found that these spheres with rough surfaces are formed by the accumulation of some nanoparticles, and no obvious disassociation of CFO is observed. By the introduction of CNTs, the microsphere size presents a slight decline with about $150-250 \mathrm{~nm}$. Some significant disassociation of CFO is recorded in the composites, possibly because acid-treated MWCNTs provide adequate active sites for the deposition of $\mathrm{Co}^{2+}$ and $\mathrm{Fe}^{3+}$ ions, leading to their redistribution during the reaction. Furthermore, some occasionally broken microspheres have been observed towards all as-obtained samples, reflecting the formation of the mesoporous hollow structure. The construction of mesoporous hollow spheres can be understood by the typical Ostwald ripening process [18]. Undoubtedly, a kind of material with a mesoporous hollow structure can possess a larger surface, which can be regarded as the active sites promoting the interfacial polarization. Moreover, the large surface can prolong the propagation path of electromagnetic waves, which is beneficial for electromagnetic energy loss because of microwave reflection and scattering. Through observing these composites, CNTs are uniformly wound on the surface of CFO microspheres accompanied with well dispersibility, indicating that CNTs and CFO are perfectly assembled, and meanwhile the agglomeration of CNTs is retarded effectively. To further confirm the mesoporous hollow structure of CFO, a few representative TEM images of composites (CFO/3\% CNTs) are displayed in Fig. 2e and 2f. It can be examined that CFO microspheres assembled by the smaller nanocrystals are connected to the reticular CNTs, in which the transparent area in the middle is inconsistent with the surrounding color, confirming the hollow interior structure in accordance with the above SEM analysis. It is found that the size of the hollow interior chamber in these microspheres is about $65 \mathrm{~nm}$. As marked in Fig. 2f, the clear lattice fringes of grains determined by the high-resolution TEM (HRTEM) images indicate that CFO is of high crystallinity, where the interplanar distance is $0.252 \mathrm{~nm}$ matched with (113) crystallographic plane of spinel ferrite $\mathrm{CoFe}_{2} \mathrm{O}_{4}$. Fig.3 exhibits the $\mathrm{N}_{2}$ adsorption-desorption isotherms and pore size distribution of as-prepared $\mathrm{CFO}$ and $\mathrm{CFO} / 3 \% \mathrm{CNTs}$ specimens. These 
isotherms are identified as IV-type, which is features of mesoporous structure materials according to the IUPAC classification [19]. These isotherms have a drastic increase at the high $\mathrm{P} / \mathrm{P}_{0}$ of $0.8-1.0$, indicating the considerable formation of mesopores due to their hollow interior [20]. As illustrated by the insert of Fig. 3, the pore size distribution of these samples displays typical mesoporous characteristics, where the pore diameter is concentrated at about $60 \mathrm{~nm}$ close to the size of hollow chamber observed by TEM images. The BET surface area is $9.0 \mathrm{~m}^{2} \mathrm{~g}^{-1}$ and $15.4 \mathrm{~m}^{2} \mathrm{~g}^{-1}$ for $\mathrm{CFO}$ and $\mathrm{CFO} / 3 \% \mathrm{CNTs}$, respectively. As-prepared samples fail to exhibit a large surface area as expected, which can be explained by the fact that the shells of $\mathrm{CoFe}_{2} \mathrm{O}_{4}$ spheres are so dense that $\mathrm{N}_{2}$ molecules can not enter the inner chamber effectively. The single point adsorption total pore volume of pores is enhanced due to the introduction of CNTs from $0.45 \mathrm{~cm}^{3} \mathrm{~g}^{-1}$ to $0.67 \mathrm{~cm}^{3} \mathrm{~g}^{-1}$. The high void volume can contribute significantly to repeated scattering and reflection of microwave, promoting the propagation path within the absorbers to gain further attenuation.

It is well known that electromagnetic absorption performances of materials are highly related to two crucial factors of impedance matching and attenuation ability. For as-obtained magnetic/dielectric materials, electromagnetic parameters of the composites can be adjusted effectively by varying loading ratio of CNTs to achieve the better impedance matching and meanwhile arouse properly large attenuation constant. Fig. 4 shows the electromagnetic parameters of the complex permittivity $\left(\varepsilon_{\mathrm{r}}\right.$ $\left.=\varepsilon^{\prime}-\mathrm{j} \varepsilon^{\prime \prime}\right)$ and permeability $\left(\mu_{\mathrm{r}}=\mu^{\prime}-\mathrm{j} \mu^{\prime \prime}\right)$ of all as-synthesized samples, where $\varepsilon^{\prime}$ and $\mu^{\prime}$ stand for the storage capability of electromagnetic wave energy, and $\varepsilon^{\prime \prime}$ and $\mu^{\prime \prime}$ represent the energy loss capability. As revealed by the Fig. 4a, the as-obtained samples, especially composites with high additive amount of CNTs, have a downward trend within the entire frequency range of 2-18 GHz. This can be explained as the fact that the polarization rotation does not have enough time to respond to the variation at the high-frequency electric field, resulting in the hysteresis phenomenon. Clearly, the $\varepsilon^{\prime}$ and $\varepsilon^{\prime \prime}$ values of composites are obviously higher compared with those of pristine CFO. Furthermore, the $\varepsilon^{\prime}$ and $\varepsilon^{\prime \prime}$ values of composites go up with increasing CNTs, which may be due to the good electrical conductivity of carbon materials. When the 
CNTs is $3 \mathrm{wt} \%$, the $\varepsilon^{\prime}$ reaches a moderate value of about 12.5 . As verified previously, the sample is most likely to exhibit the excellent microwave absorption capacity with the magnitude of $\varepsilon^{\prime}$ in the range of 10-20 [21]. However, there has been a remarkable increase in the $\varepsilon^{\prime}$ and $\varepsilon^{\prime \prime}$ as CNTs content further increases to $5 \mathrm{wt} \%$, which is not conducive to the balance of complex permittivity and permeability. This can be easily understood by the theory of free electrons and skin effect [7]. Since CFO/CNTs composites with a high content of CNTs can present a high electrical conductivity, which means its resistivity is low corresponding to a high $\varepsilon "$. Therefore, it can be inferred that a suitable permittivity can be achieved which is favorable for obtaining the outstanding microwave absorption performances by adjusting the amount of CNTs. But too high permittivity can cause the electromagnetic wave to reflect on the surface at the air-absorber interface, which is not conducive to electromagnetic wave absorption. Additionally, the introduction of CNTs can increase interfaces and polarization charges on the composites. The increasing interfacial polarization and associated relaxation are beneficial for the increase of dielectric loss. The dielectric loss tangent $\tan \delta_{\mathrm{e}}$ of composites is exhibited in Fig. 4(e), keeping an upward tendency in $2-18 \mathrm{GHz}$, which can be caused by varying polarization relaxation mechanisms due to the presence of carbon materials. The Cole-Cole semicircles derived from the plots of $\varepsilon^{\prime}$ versus $\varepsilon^{\prime \prime}$ represent Debye relaxation process to confirm the polarization relaxation behaviors. On the basis of classical Debye theory, the relationship between $\varepsilon^{\prime}$ and $\varepsilon^{\prime \prime}$ may be described below [22]:

$$
\left(\varepsilon^{\prime}-\frac{\varepsilon_{s}+\varepsilon_{\infty}}{2}\right)^{2}+\left(\varepsilon^{\prime \prime}\right)^{2}=\left(\frac{\varepsilon_{s}-\varepsilon_{\infty}}{2}\right)^{2}
$$

where $\varepsilon_{\mathrm{s}}$ and $\varepsilon_{\infty}$ represent the static dielectric constant and dielectric constant at the infinite frequency, respectively. Generally, a single semicircle denoted as Cole-Cole symbolizes one Debye polarization relaxation process. Fig. 5 shows relation curves of $\varepsilon^{\prime}$ versus $\varepsilon "$ of pure $\mathrm{CFO}$ and $\mathrm{CFO} / \mathrm{CNT}$ s composites in 2-18 GHz. From Fig. 5a, the Cole-Cole plot of pure $\mathrm{CoFe}_{2} \mathrm{O}_{4}$ exhibits a completely disordered behavior, i.e., no obvious dielectric relaxation process, indicating that interface polarization contributes little to dielectric loss. This similar results have been also observed in 
$\mathrm{Fe}_{3} \mathrm{O}_{4}$ microspheres [23]. Therefore, with the gradual increase in CNTs, some relative arcs from Cole-Cole curves appear, confirming the existence of multiple dielectric relaxation processes along with the three samples [7]. The multiple relaxation processes are basically caused by the defect polarization, functional groups, special structure of porous $\mathrm{CoFe}_{2} \mathrm{O}_{4}$ hollow spheres and multiple interfaces between $\mathrm{CoFe}_{2} \mathrm{O}_{4}$ and CNTs where a considerable amount of space charges accumulates at the heterogeneous interface, improving the dielectric loss of composites.

As observed by Fig. $4 \mathrm{c}$ and $4 \mathrm{~d}, \mu^{\prime}$ and $\mu^{\prime \prime}$ plots of the four samples are partially overlapped and accompanied by several formants which suggest that the addition of CNTs with a small amount does not contribute much to the magnetic loss of CFO. In particular, $\mu^{\prime}$ value of all samples slightly goes down from 1.6 to 1.0 between 2.0 to 10.5 GHz, and then fluctuates around approximately 1.2 with the increasing frequency and meanwhile $\mu^{\prime \prime}$ varies with some slight fluctuations within the entire frequency range. Interestingly enough, the $\mu^{\prime \prime}$ exhibits negative values at the high frequency, which be explained by the fact that EM energy is radiated out from $\mathrm{CFO} / \mathrm{CNTs}$ composites due to the motion of charges, and this similar phenomena have been also reported in other work [24]. The magnetic loss tangent $\tan \delta_{\mathrm{m}}$ value of pure $\mathrm{CoFe}_{2} \mathrm{O}_{4}$ is mostly higher than that of the other three composites, as exhibited by Fig. 4f, indicating its strong magnetic loss ability. From the composites, the decrease in $\tan \delta_{\mathrm{m}}$ value is ascribed to the non-magnetism of CNTs. As a rule, the magnetic loss is generally associated with the exchange resonance, natural resonance as well as eddy current loss over the microwave frequency range. Some obvious resonance peaks are found in the curves of $\tan \delta_{\mathrm{m}}$, which can be ascribed to the exchange resonance and natural resonance. In addition, the eddy current effect is defined as follows.

$$
C_{0}=\mu^{\prime \prime}\left(\mu^{\prime}\right)^{-2} f^{-1}=2 \pi \mu_{0} d^{2} \sigma / 3
$$

where $\mu_{0}$ and $\sigma$ are the permeability of vacuum and the electric conductivity of the composites, respectively. When the magnetic loss is only brought about by the eddy 
current loss, $C_{0}$ should maintain a constant within the measured frequency range. As depicted in Fig. 6, $C_{0}$ is almost constant at the high frequency range of 12-18 GHz, indicating eddy current effect plays a dominant role in the magnetic loss. Consequently, it turns out that magnetic loss is mainly brought out by resonance effect and eddy current loss in the corresponding frequency range of 2-12 GHz and 12-18 GHz, respectively. In comparison, the value of $\tan \delta_{\mathrm{m}}$ is far lower than that of $\tan \delta_{\mathrm{e}}$ in most frequency, which demonstrates that the microwave absorption ability of these composites is primarily determined by dielectric loss in most case.

Usually, the reflection loss (RL) is carried out to estimate the intensity of microwave absorption. The commercial standards require that RL value should be lower than $-10 \mathrm{~dB}$, defined as the effective absorption bandwidth, within the range of microwave frequency, which means that $90 \%$ of EM waves can be absorbed and attenuated. According to the transmission line theory, the RL values can be calculated as [17].

$$
\begin{aligned}
& R L(d B)=20 \log \left|\frac{Z_{\text {in }}-Z_{0}}{Z_{\text {in }}+Z_{0}}\right| \\
& Z_{\text {in }}=Z_{0} \sqrt{\frac{\mu_{r}}{\varepsilon_{r}}} \tanh \left[j\left(\frac{2 \pi f d}{c}\right) \sqrt{\mu_{r} \varepsilon_{r}}\right]
\end{aligned}
$$

where $Z_{\text {in }}$ is the input impedance of the absorber, $Z_{0}$ is the impedance of free space, $\mu_{\mathrm{r}}$ and $\varepsilon_{\mathrm{r}}$ are the relative permeability and permittivity, respectively, $f$ is the frequency of microwaves, $d$ is the thickness of the absorber, and $c$ is the velocity of light. Fig. 7 shows the calculated results of RL of the CFO/CNTs composites with different loading ratios of CNTs at different thicknesses within the whole frequency range. For pure $\mathrm{CoFe}_{2} \mathrm{O}_{4}$ shown in Fig. 7a, nearly all $\mathrm{RL}$ values are above $-10 \mathrm{~dB}$ by changing the thickness of $1-5 \mathrm{~mm}$ over the entire frequency range. This displays that the microwave absorption ability of sole $\mathrm{CoFe}_{2} \mathrm{O}_{4}$ magnetic materials is unsatisfactory. The good news is that the microwave absorption properties are enhanced by adding a certain amount of CNTs into the $\mathrm{CoFe}_{2} \mathrm{O}_{4}$. By introducing weight ratio of $1 \% \mathrm{CNTs}$, the composites possess an optimal absorption peak of about $-28.07 \mathrm{~dB}$ at $8.09 \mathrm{GHz}$, and the corresponding effective absorption bandwidth reaches $4 \mathrm{GHz}$ from 7.03 to 
$11.03 \mathrm{GHz}$ with the thickness of $2.8 \mathrm{~mm}$, as exhibited by Fig. 7b. When CNTs continues to increase to $3 \mathrm{wt} \%$, the superior microwave absorption performances (shown in Fig. 7c) has been observed in the composites where the $\mathrm{RL}_{\min }$ reaches $-46.65 \mathrm{~dB}$ at $14.4 \mathrm{GHz}$ corresponded to the effective absorption bandwidth of 4.91 $\mathrm{GHz}$ from 12.41 to $17.32 \mathrm{GHz}$ only at a thin thickness of $1.5 \mathrm{~mm}$. This can be explained by the synthetic effect of magnetic material of $\mathrm{CoFe}_{2} \mathrm{O}_{4}$ and dielectric material of carbon. However, the microwave absorption ability of $\mathrm{CoFe}_{2} \mathrm{O}_{4} / \mathrm{CNT}$ s is basically invalid when the load concentration of CNTs increases further to 5\%. In other words, the microwave absorption performance of composites becomes poor with a high CNTs content, as demonstrated by Fig. 7d. The results demonstrate that microwave absorption properties of $\mathrm{CoFe}_{2} \mathrm{O}_{4} / \mathrm{CNT}$ composites can be tuned by simply varying the additive amount of CNTs, in which this composite with $3 \mathrm{wt} \%$ CNTs displays the champion microwave absorption properties. In detail, microwave absorption properties of some similar $\mathrm{CoFe}_{2} \mathrm{O}_{4}$-based composites reported in recent years have been listed in Table1. In contrast, $\mathrm{CoFe}_{2} \mathrm{O}_{4} / \mathrm{CNTs}$ composites in the present work possess distinct advantages by overall consideration of specific $\mathrm{RL}_{\mathrm{min}}$ and effective absorption bandwidth. The as-obtained CFO/3\% CNTs shows the highest specific RLmin of $-31.1 \mathrm{~dB} \cdot \mathrm{mm}^{-1}$ and a relatively wide effective absorption bandwidth.

Table 1 Microwave absorption performance of some $\mathrm{CoFe}_{2} \mathrm{O}_{4}$-based materials in recent years and present work.

\begin{tabular}{|c|c|c|c|c|c|}
\hline sample & $\begin{array}{l}R_{\text {min }} \\
(\mathrm{dB})\end{array}$ & $\begin{array}{l}\text { Thickness } \\
\text { (mm) }\end{array}$ & $\begin{array}{l}\text { Specific RLmin } \\
\left(\mathrm{dB} \cdot \mathrm{mm}^{-1}\right)\end{array}$ & $\begin{array}{l}\text { Effective bandwidth } \\
\qquad(<-10 \mathrm{~dB})(\mathrm{GHz})\end{array}$ & Reference \\
\hline $\mathrm{RGO} / \mathrm{CoFe}_{2} \mathrm{O}_{4}$ & -47.9 & 2.3 & -20.8 & 4.9 & {$[25]$} \\
\hline SWCNTS/CoFe2O4 & -30.7 & 2.0 & -15.4 & 7.2 & {$[26]$} \\
\hline $\mathrm{G} / \mathrm{BaFe}_{12} \mathrm{O}_{19} / \mathrm{CoFe}_{2} \mathrm{O}_{4}$ & -32.4 & 3.0 & -10.8 & 3.0 & {$[14]$} \\
\hline $\mathrm{CoFe} 2 \mathrm{O} 4 / \mathrm{CCNTS}$ & -14 & $2.5-3.0$ & $-(5.6-4.7)$ & 4.0 & {$[27]$} \\
\hline $\mathrm{CoFe} 2 \mathrm{O} 4 / \mathrm{RGO}$ & -40 & 4.0 & -10.0 & 2.7 & {$[28]$} \\
\hline $\mathrm{CoFe}_{2} \mathrm{O}_{4} / \mathrm{CNTs}$ & -32.8 & 2.0 & -16.4 & 5.7 & [16] \\
\hline $\mathrm{CoFe}_{2} \mathrm{O}_{4} / \mathrm{G}$ & -42 & 2.0 & -21.0 & 4.59 & {$[6]$} \\
\hline $\mathrm{CoFe}_{2} \mathrm{O}_{4} / \mathrm{CNFs}$ & -14 & 3.5 & -4.0 & $3.6(\mathrm{~d}=2.5 \mathrm{~mm})$ & [29] \\
\hline $\mathrm{CoFe} 2 \mathrm{O} 4-\mathrm{HNP} / \mathrm{G}$ & -50.2 & 2.0 & -25.1 & 3.2 & {$[30]$} \\
\hline $\mathrm{RGO} / \mathrm{CoFe}_{2} \mathrm{O}_{4}$ & -50.0 & 2.3 & -21.7 & $6.16(\mathrm{~d}=2.0 \mathrm{~mm})$ & [13] \\
\hline $\mathrm{C} / \mathrm{CoFe}_{2} \mathrm{O}_{4}$ & -49.6 & 2.5 & -19.8 & --- & {$[8]$} \\
\hline
\end{tabular}


Abbreviations: RGO: reduced graphene oxide, SWCNTs: Single-walled carbon nanotubes, G: graphene, CCNTs: Coiled carbon nanotubes, CNTs: carbon nanotubes, CNFs: carbon nanofibers and HNP: Hollow nanoparticles. Specific RL $\mathrm{min}_{\text {in }}$ represents the minimum reflection loss per thickness.

As expected, the absorption peaks of the four samples move toward low frequency with the increasing thickness of $1-5 \mathrm{~mm}$. This phenomenon can be related to the electromagnetic cancellation effect, which is described as below

$$
t_{m}=\frac{n \lambda}{4}=\frac{n c}{4 f \sqrt{\left|\mu_{r}\right|\left|\varepsilon_{r}\right|}} \quad(n=1,3,5 \ldots)
$$

where $t_{\mathrm{m}}$ is the thickness of absorber, $\lambda$ is the wavelength of the electromagnetic wave, $c$ is the light velocity, $f$ is the microwave frequency, $\mu_{\mathrm{r}}$ and $\varepsilon_{\mathrm{r}}$ are complex permeability and permittivity, respectively. As shown in Fig. 8, almost all experimental points marked by the heart type at the peak frequency of $R L_{\min }$ happen to be at the location matched with the simulated thickness on frequency at $n=1$ of $\mathrm{CFO} / 3 \% \mathrm{CNTs}$, which indicates that the corresponding frequency with $\mathrm{RL}_{\min }$ peak mainly originates from the quarter-wavelength cancellation model.

As analyzed by the section mentioned above, the microwave absorption performance of composites can be greatly optimized by adjusting the composition ratio of CNTs to $\mathrm{CoFe}_{2} \mathrm{O}_{4}$ materials. Compared with pure $\mathrm{CoFe}_{2} \mathrm{O}_{4}$, electromagnetic wave can enter into the composites and be dissipated effectively. The detailed mechanisms of the enhanced microwave absorption performance can be discussed based on the impedance matching and attenuation characteristics as follows. According to the propagation mechanism of the absorbers, when an electromagnetic wave is projected onto the surface of the absorbing layer, it should firstly fulfil the requirement that the electromagnetic wave can enter into the interior of the layer to the maximum extent. In view of this, it is required that the absorbing material should possess a superior impedance matching, that is, the surface of the material should meet special boundary conditions, where requires the intrinsic impedance of the absorber to be infinitely close to that of the air $\left(Z=Z_{\text {in }} / Z_{0}=1\right)$. After the incident 
electromagnetic wave enters the interior of the medium without reflection, electromagnetic energy will be consumed by the absorbent as much as possible. The loss modes of the waves mostly cover dielectric loss, magnetic loss, as well as physical loss caused by the structure of the materials, like multiple scattering and reflection. In light of this mentioned above, the champion microwave absorption capability of the materials can be achieved by obtaining satisfactory impedance matching and attenuation loss characteristics.

The attenuation constant $\alpha$ is usually a response to the overall dissipation characteristics of the materials calculated using the formula below [21]

$$
\alpha=\frac{\sqrt{2} \pi f}{c} \times \sqrt{\left(\mu^{\prime \prime} \varepsilon^{\prime \prime}-\mu^{\prime} \varepsilon^{\prime}\right)+\sqrt{\left(\mu^{\prime \prime} \varepsilon^{\prime \prime}-\mu^{\prime} \varepsilon^{\prime}\right)^{2}+\left(\mu^{\prime \prime} \varepsilon^{\prime}+\mu^{\prime} \varepsilon^{\prime \prime}\right)^{2}}}
$$

As a rule, large $\alpha$ value can be regarded as a direct reflection of the strong attenuation capability of microwave. As demonstrated by Equ. (5), higher values of $\varepsilon^{\prime \prime}$ and $\mu^{\prime \prime}$ mean high attenuation capability of the materials. From the point of view, the composite of $\mathrm{CFO} / 5 \% \mathrm{CNTs}$ has the maximum value of $\alpha$, followed by the $\mathrm{CFO} / 3 \%$ CNTs sample, as can be seen from Fig. 9. Although the sample of $\mathrm{CFO} / 5 \% \mathrm{CNTs}$ has a large $\alpha$ value, it exhibits the poor microwave absorption performances mentioned above. The main reason can be considered by the degree of impedance matching since impedance matching and electromagnetic wave attenuation jointly determine the reflective loss capability of the material. The degree of impedance matching is evaluated by the delta values $(\Delta)$ with the following equation:

$$
\begin{gathered}
\Delta=\left|\sinh ^{2}(K f d)-M\right| \\
K=\frac{4 \pi \sqrt{\mu_{r}^{\prime} \varepsilon_{r}^{\prime}}}{c} \frac{\sin \frac{\delta_{e}+\delta_{m}}{2}}{\cos \delta_{e} \cos \delta_{m}} \\
M=\frac{4 \mu_{r}^{\prime} \cos \delta_{e} \varepsilon_{r}^{\prime} \cos \delta_{m}}{\left(\mu_{r}^{\prime} \cos \delta_{e}-\varepsilon_{r}^{\prime} \cos \delta_{m}\right)^{2}+\left(\tan \frac{\delta_{m}-\delta_{e}}{2}\right)^{2}\left(\mu_{r}^{\prime} \cos \delta_{e}+\varepsilon_{r}^{\prime} \cos \delta_{m}\right)^{2}}
\end{gathered}
$$

where $\delta_{\mathrm{e}}=\arctan \left(\varepsilon^{\prime \prime} / \varepsilon^{\prime}\right)$ and $\delta_{\mathrm{m}}=\arctan \left(\mu^{\prime \prime} / \mu^{\prime}\right)$ are the tangent of dielectric loss and magnetic loss, respectively. Usually, the larger $\Delta$ value means poorer electromagnetic 
impedance matching. In the actual application, the delta values $(\Delta)$ less than 0.4 are usually employed as criteria for evaluating the degree of superior impedance matching [31]. As illustrated in Fig. 10, the colored area, namely effective impedance matching region, with $\Delta$ values for the four samples is changed obviously by modulating the loading concentration of CNTs. Note that the delta values show the same tendency with the reflection loss. CFO/3\% CNTs composites possess the largest area corresponding to $\Delta$ below 0.4 , indicating the better degree of impedance matching. However, the impedance matching degree of composites becomes increasingly inferior as CNTs content increases to 5\%. Since the reflection of EM waves on the surfaces of composites-paraffin will increases with an excessively high loading content of carbon which will give rise to the unbalance of magnetic loss and dielectric loss, eventually resulting in the mismatch of impedance. Therefore, although the $\mathrm{CFO} / 5 \% \mathrm{CNT}$ s has the highest attenuation constant, the $\mathrm{CFO} / 3 \% \mathrm{CNTs}$ exhibits the champion microwave absorption ability origin from the synergistic effect of suitable impedance matching and adequate attenuation constant.

Overall, the microwave absorption mechanism of CFO/CNTs samples can be summarized as follows. Firstly, the acidification surface of CNTs can provide much more active sites for microwave reflection and scattering, promoting the microwave repeated absorption process more efficiently. Meanwhile, conductive paths can be constructed with a large amount of CNTs, which is helpful for the conductivity loss. Secondly, mesoporous hollow structure $\mathrm{CoFe}_{2} \mathrm{O}_{4}$ microspheres can extend the microwave propagation path within the samples and further improve the dissipation of microwave energy. Besides that, the interface of composites due to distinguishing dielectric properties between $\mathrm{CoFe}_{2} \mathrm{O}_{4}$ and CNTs will lead to charge accumulation at the heterogeneous interface, resulting in the increasing interfacial polarization. More importantly, the influence of resonance effect and eddy current loss on the ferromagnetic behavior of as-prepared composites cannot be underestimated. In brief, the introduction of carbon nanotubes is beneficial to optimize the impedance matching and attenuation characteristics of $\mathrm{CoFe}_{2} \mathrm{O}_{4}$ material and achieve the effective complementarities of magnetic loss and dielectric loss in the composites. 


\section{Conclusion}

In summary, the $\mathrm{CoFe}_{2} \mathrm{O}_{4}$ and carbon nanotubes composites with the different weight ratios of carbon nanotubes have been prepared through a facile solvothermal method. It is observed that the carbon nanotubes are uniformly dispersed in the mesoporous $\mathrm{CoFe}_{2} \mathrm{O}_{4}$ hollow microspheres. The dielectric constant has a significant enhancement by varying the loadings of carbon nanotubes in the composites. The $\varepsilon^{\prime \prime}$ of composites with $3 \mathrm{wt} \%$ CNTs loading is almost nine times as large as that of pure $\mathrm{CoFe}_{2} \mathrm{O}_{4}$. The minimum reflection loss of $-46.65 \mathrm{~dB}$ at $14.4 \mathrm{GHz}$ and its corresponding effective absorption bandwidth of $4.91 \mathrm{GHz}(12.41$ to $17.32 \mathrm{GHz})$ are achieved with a thin thickness of $1.5 \mathrm{~mm}$ when the load concentration of CNTs is 3 wt $\%$, which are superior to those of pure $\mathrm{CoFe}_{2} \mathrm{O}_{4}$ as well as other composites of $\mathrm{CoFe}_{2} \mathrm{O}_{4}$. The enhanced tunable microwave absorption performance can be explained by the increasing interfacial polarization and dielectric loss because of the introduction of CNTs, the effective complementarities of magnetic loss and dielectric loss. These results indicate that the composites of $\mathrm{CoFe}_{2} \mathrm{O}_{4}$ and carbon nanotubes can be regarded as a potential material in high-performance microwave absorption application.

\section{Acknowledgements}

This work was financially supported by the Foundation of Educational Commission of Anhui Province (KJ2018A0393), and Anhui Provincial Natural Science Foundation (1908085QA36 and 1908085QF293).

\section{References}

[1] X.F. Zhang, X.L. Dong, H. Huang, Y.Y. Liu, W.N. Wang, X.G. Zhu, B. Lv, J.P. Lei, C.G. Lee, Appl. Phys. Lett., 89 (2006) 053115.

[2] Q.M. Hu, R.L. Yang, Z.C. Mo, D.W. Lu, L.L. Yang, Z.F. He, H. Zhu, Z.K. Tang, X.C. Gui, Carbon, 153 (2019) 737-744.

[3] X. Wang, F. Pan, Z. Xiang, Q.W. Zeng, K. Pei, R.C. Che, W. Lu, Carbon, 157 (2020) 130-139.

[4] R.C. Che, L.-M. Peng, X.F. Duan, Q. Chen, X.L. Xue, Adv. Mater., 16 (2004) 
401-405.

[5] N.N. Wu, D.M. Xu, F. Yang, W. Liu, J.R. Liu, Ind. Eng. Chem. Res., 58 (2019) 6446-6455.

[6] S.S. Wang, Y. Zhao, H.L. Xue, J.R. Xie, C.H. Feng, H.S. Li, D.X. Shi, S. Muhammad, Q.Z. Jiao, Mater. Lett., 223 (2018) 186-189.

[7] X.Q. Cui, W. Liu, W.H. Gu, X.H. Liang, G.B. Ji, Inorg. Chem. Front., 6 (2019) 590-597.

[8] L. Huang, J.J. Li, Z.J. Wang, Y.B. Li, X.D. He, Y. Yuan, Carbon, 143 (2019) 507-516.

[9] S. Golchinvafa, S.M. Masoudpanah, M. Jazirehpour, J. Alloys Compd., 809 (2019) 151746.

[10] J.J. Li, Y.Z. Feng, Y.F. Wu, Y. Yuan, Physica B, 561 (2019) 16-22.

[11] S.L. Zhang, Q.Z. Jiao, Y. Zhao, H.S. Li, Q. Wu, J. Mater. Chem. A, 2 (2014) 18033-18039.

[12] T. Shang, Q.S. Lu, L.M. Chao, Y.L. Qin, Y.H. Yun, G.H. Yun, Appl. Surf. Sci., 434 (2018) 234-242.

[13] X.Y. Zhang, L. Xia, B. Zhong, H. Yang, B. Shi, L.N. Huang, Y.N. Yang, X.X. Huang, J. Alloys Compd., 799 (2019) 368-376.

[14] H.B. Yang, T. Ye, Y. Lin, M. Liu, Appl. Surf. Sci., 357 (2015) 1289-1293.

[15] Y.B. Zainal, Dedi, A. Manaf, Key Eng. Mater., 855 (2020) 322-329.

[16] S.L. Zhang, Z.W. Qi, Y. Zhao, Q.Z. Jiao, X. Ni, Y.J. Wang, Y. Chang, C. Ding, J. Alloys Compd., 694 (2017) 309-312.

[17] M.J. Lu, J. Wang, X.G. Su, Q.L. Wu, T.Y. Yan, X.X. Zhang, Mater. Lett., 253 (2019) 46-49.

[18] Y. Wang, D. Su, A. Ung, J.H. Ahn, G. Wang, Nanotechnology, 23 (2012) 055402.

[19] R. Qiang, Y.C. Du, Y. Wang, N. Wang, C.H. Tian, J. Ma, P. Xu, X.J. Han, Carbon, 98 (2016) 599-606.

[20] X.-J. Zhang, J.-Q. Zhu, P.-G. Yin, A.-P. Guo, A.-P. Huang, L. Guo, G.-S. Wang, Adv. Funct. Mater., 28 (2018) 1800761.

[21] Y. Cheng, Y. Li, G.B. Ji, B. Quan, X.H. Liang, Z.X. Zhao, J.M. Cao, Y.W. Du, J. 
Alloys Compd., 708 (2017) 587-593.

[22] K. Qian, Z.J. Yao, H.Y. Lin, J.T. Zhou, A.A. Haidry, T.B.H. Qi, W.J. Chen, X.L. Guo, Ceram. Int., 46 (2020) 227-235.

[23] Y.C. Du, W.W. Liu, R. Qiang, Y. Wang, X.J. Han, J. Ma, P. Xu, ACS Appl. Mater. Inter., 6 (2014) 12997-13006.

[24] X. Li, L.M. Yu, W.K. Zhao, Y.Y. Shi, L.J. Yu, Y.B. Dong, Y.F. Zhu, Y.Q. Fu, X.D. Liu, F.Y. Fu, Chem. Eng. J., 379 (2020) 122393.

[25] M. Zong, Y. Huang, H.W. Wu, Y. Zhao, Q.F. Wang, X. Sun, Mater. Lett., 114 (2014) 52-55.

[26] G. Li, L.M. Sheng, L.M. Yu, K. An, W. Ren, X.L. Zhao, Mater. Sci. Eng. B, 193 (2015) 153-159.

[27] J.T. Feng, Y.C. Wang, Y.H. Hou, J.B. Li, L.C. Li, Ceram. Int., 42 (2016) 17814-17821.

[28] Z.Y. Liu, G.L. Xu, M. Zhang, K. Xiong, P.Y. Meng, J. Mater. Sci-Mater. El., 27 (2016) 9278-9285.

[29] Y.J. Li, M.W. Yuan, H.H. Liu, G.B. Sun, J. Alloys Compd., 826 (2020) 154147.

[30] F. Yan, S. Zhang, X. Zhang, C.Y. Li, C.L. Zhu, X.T. Zhang, Y.J. Chen, J. Mater. Chem. C, 6 (2018) 12781-12787.

[31] D.W. Liu, Y.C. Du, F.Y. Wang, Y.H. Wang, L.R. Cui, H.H. Zhao, X.J. Han, Carbon, 157 (2020) 478-485. 


\section{Figure captions}

Fig. 1. XRD patterns of as-obtained $\mathrm{CoFe}_{2} \mathrm{O}_{4} / \mathrm{CNTs}$ composites with various mass ratios.

Fig. 2. SEM image of the composites with CFO (a), CFO/1\% CNTs (b), CFO/3\% CNTs (c) and CFO/5\% CNTs (d). (e, f) TEM images of CFO/3\% CNTs.

Fig. 3. $\mathrm{N}_{2}$ adsorption-desorption isotherms of all as-prepared samples. The corresponding pore size distribution is shown in the insert.

Fig. 4. Frequency dependence of (a) $\varepsilon^{\prime}$, (b) $\varepsilon^{\prime \prime}$, (c) $\mu^{\prime}$, (d) $\mu^{\prime \prime}$, (e) $\tan \delta_{\mathrm{e}}$ and (f) $\tan \delta_{\mathrm{m}}$ for CFO/CNTs composites.

Fig. 5. Typical Cole-Cole semicircle of composites with various load concentration of carbon nanotubes.

Fig. 6. The $C_{0}$ constant of eddy current loss versus frequency for all as-prepared samples.

Fig. 7. Three-dimensional reflection loss with different frequency and thickness for samples (a) CFO (a), (b) CFO/1\% CNTs, (c) CFO/3\% CNTs and (d) CFO/5\% CNTs . Fig. 8. (a) Frequency dependence of reflection loss and (b) corresponding matching thickness versus frequency plots of $\mathrm{CFO} / 3 \% \mathrm{CNTs}$ under $\lambda / 4$ model (the red heart type represents experimental data and green line represents fitting plots).

Fig. 9. Frequency dependence of attenuation constant $\alpha$ of all as-prepared samples.

Fig. 10. Calculated delta value maps for samples (a) $\mathrm{CFO}$, (b) $\mathrm{CFO} / 1 \% \mathrm{CNTs}$, (c) $\mathrm{CFO} / 3 \% \mathrm{CNTs}$ and (d) $\mathrm{CFO} / 5 \% \mathrm{CNTs}$ with various absorber thicknesses in 2.0-18.0 GHz. 


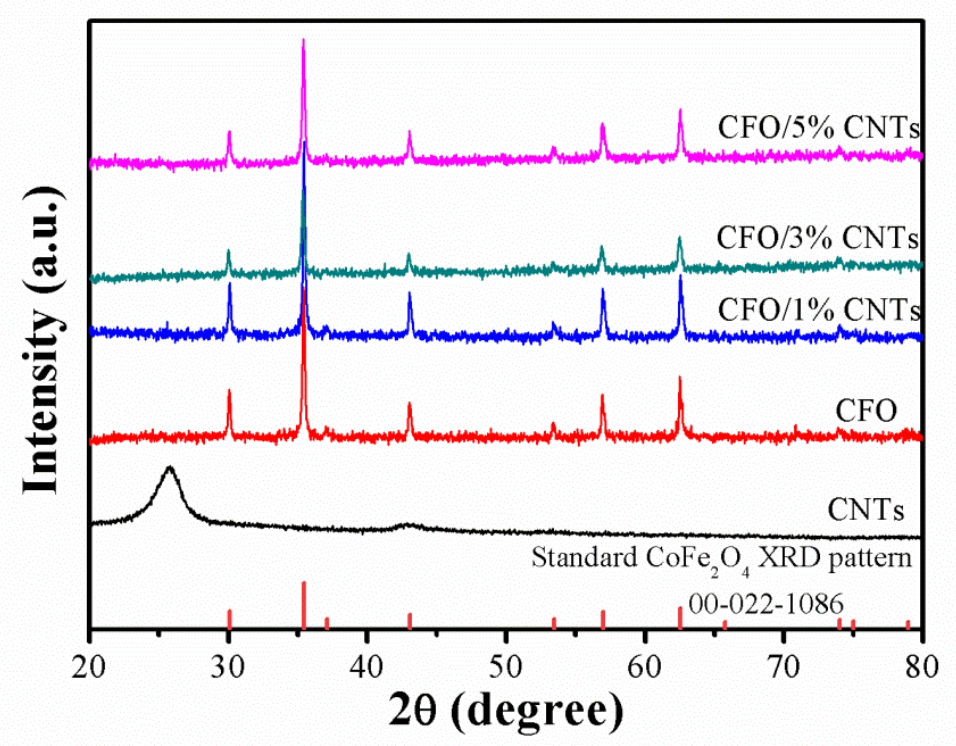

Fig. 1
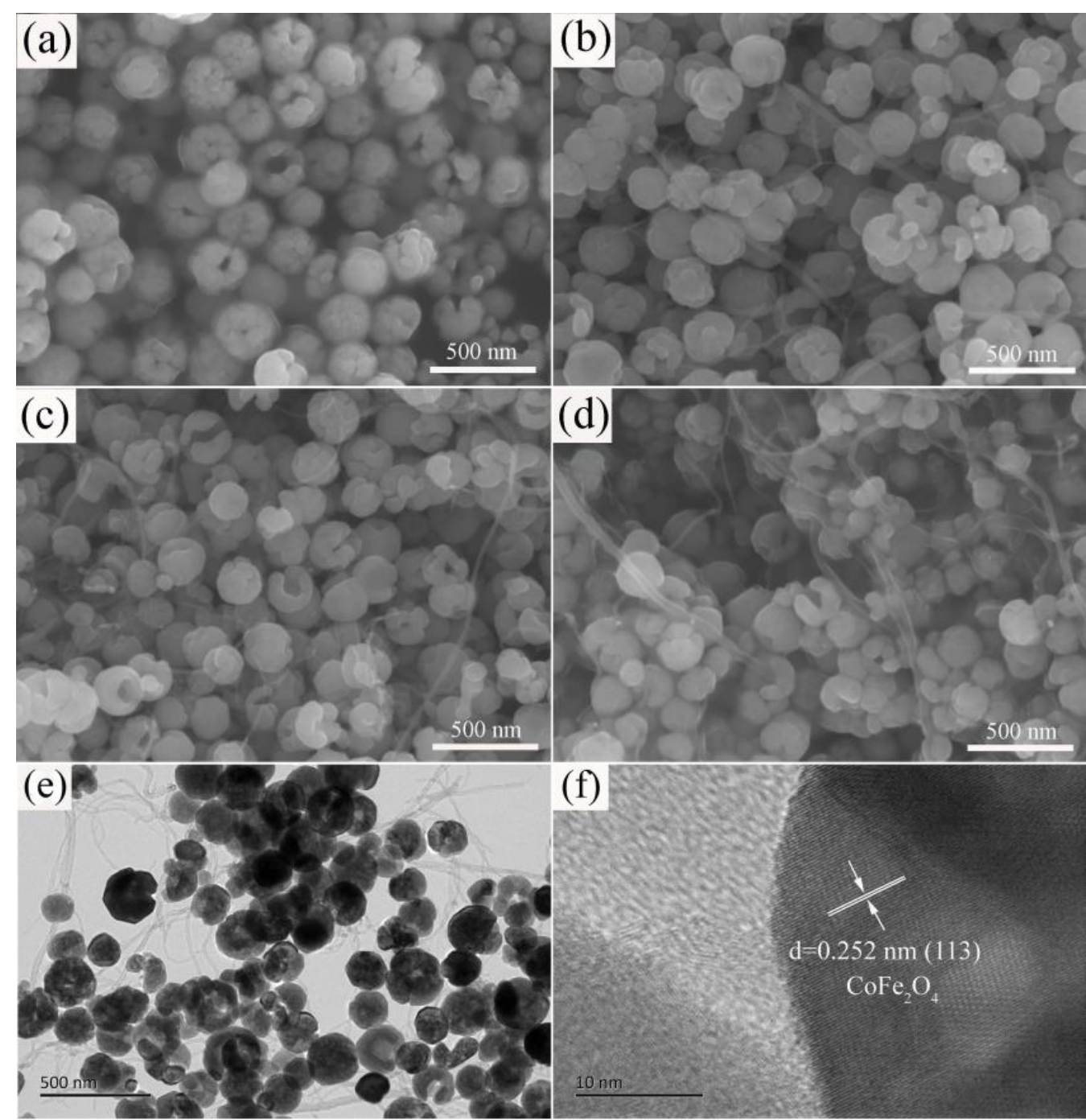

(f)

Fig. 2 


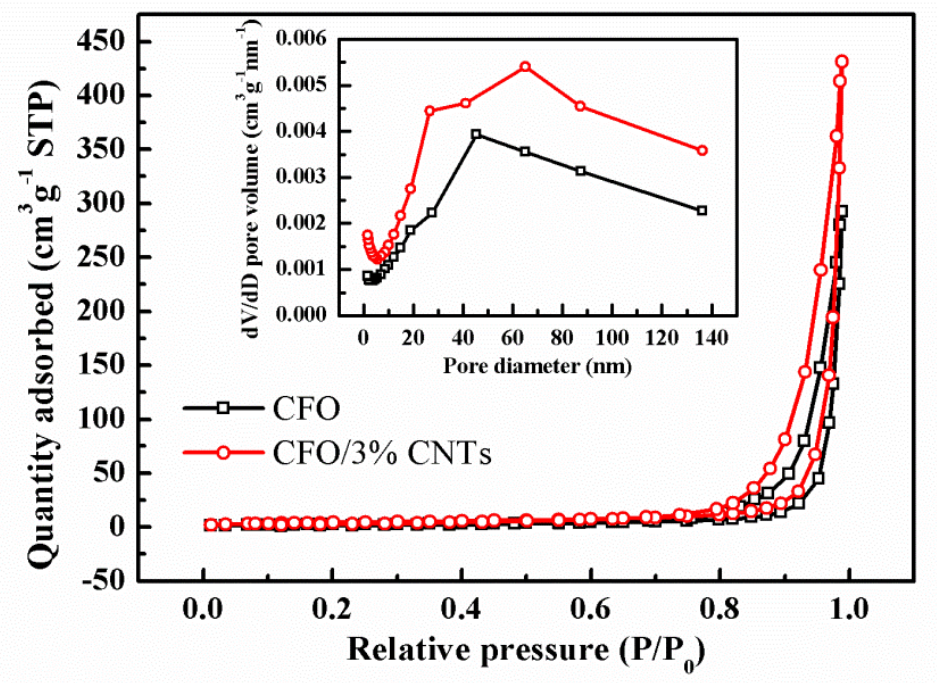

Fig. 3
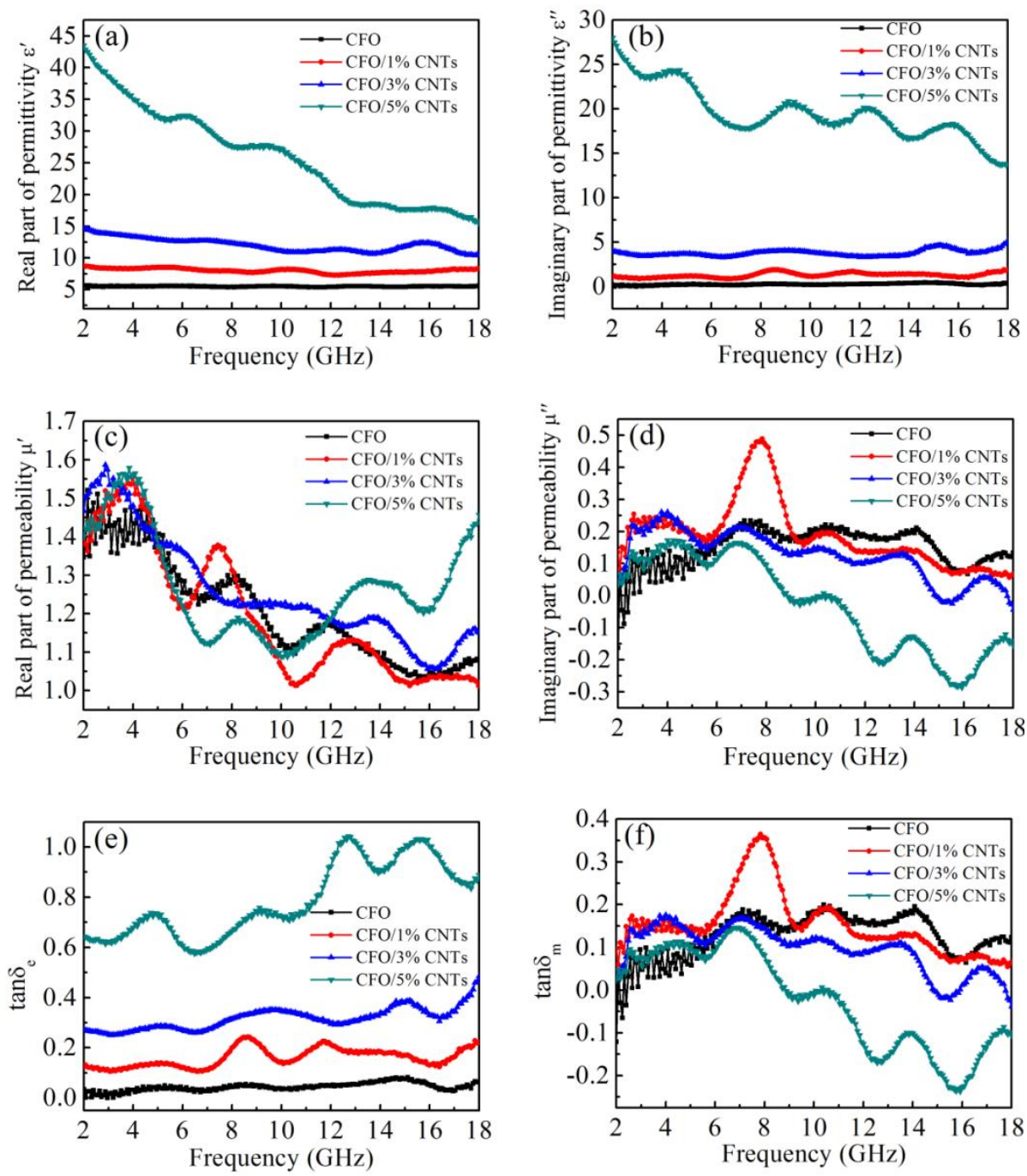

Fig. 4 

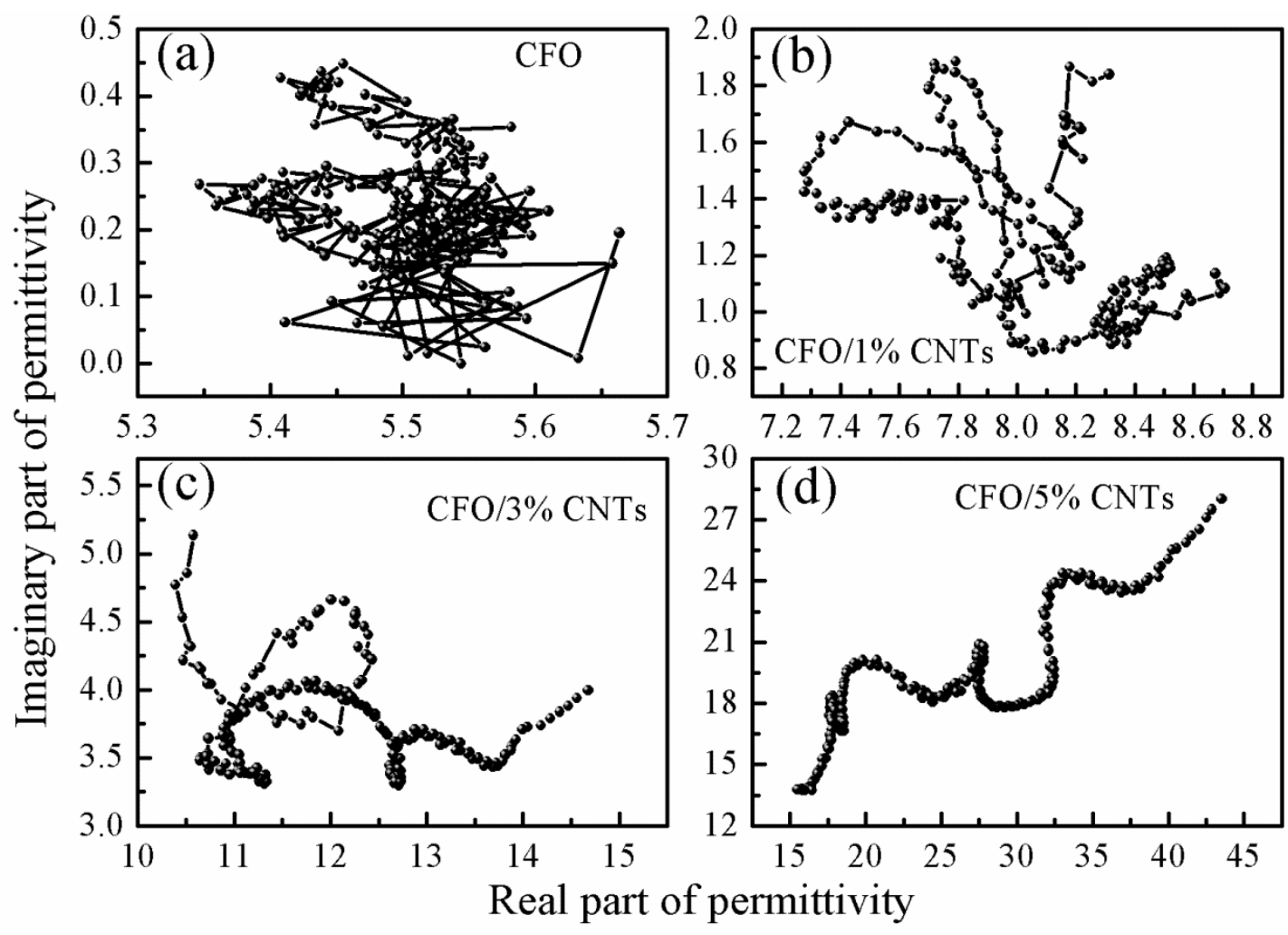

Fig. 5

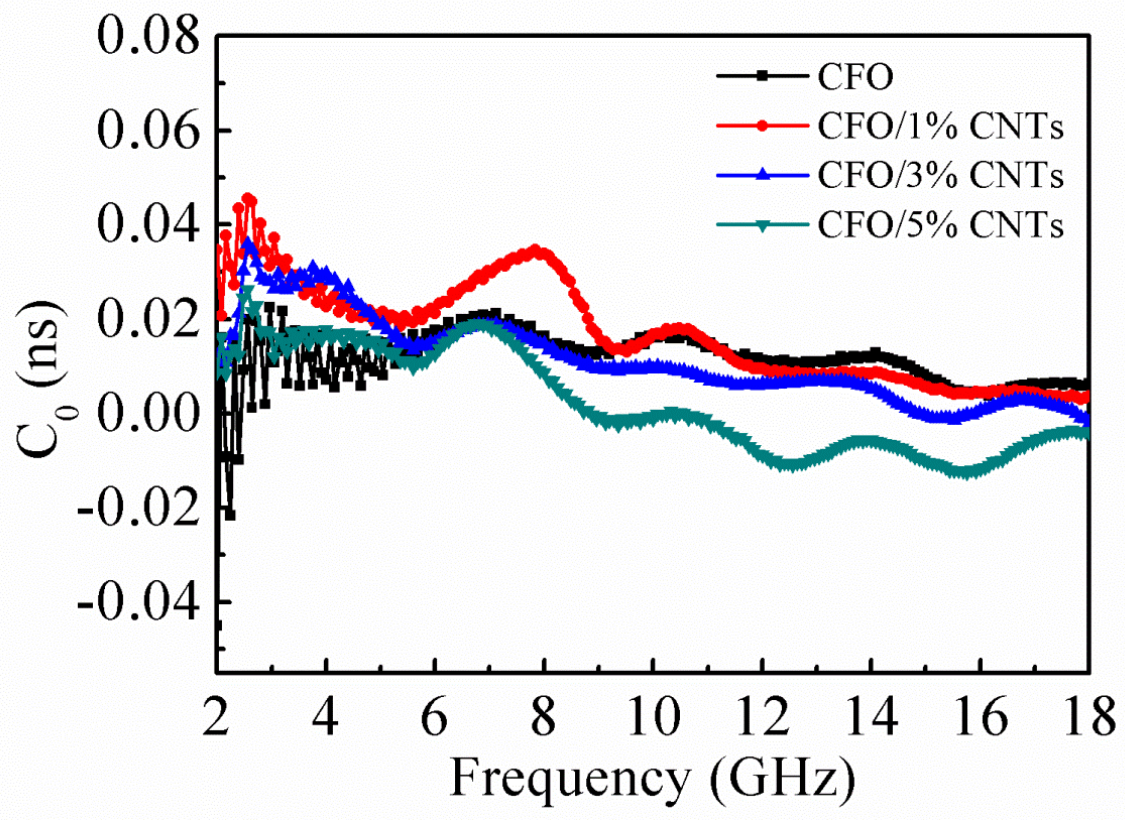

Fig. 6 
(a)

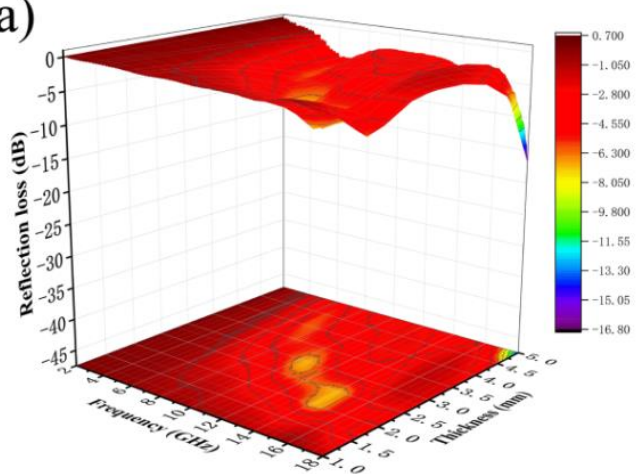

(c)

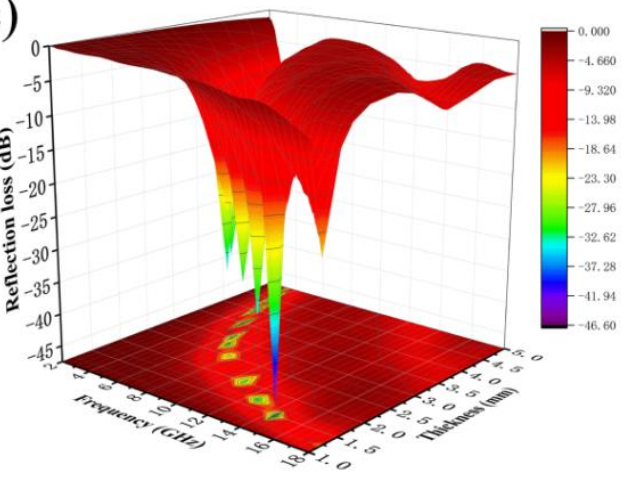

(b)

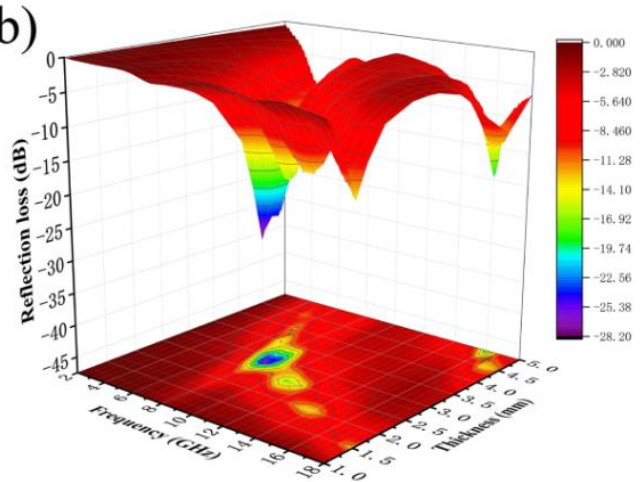

(d)

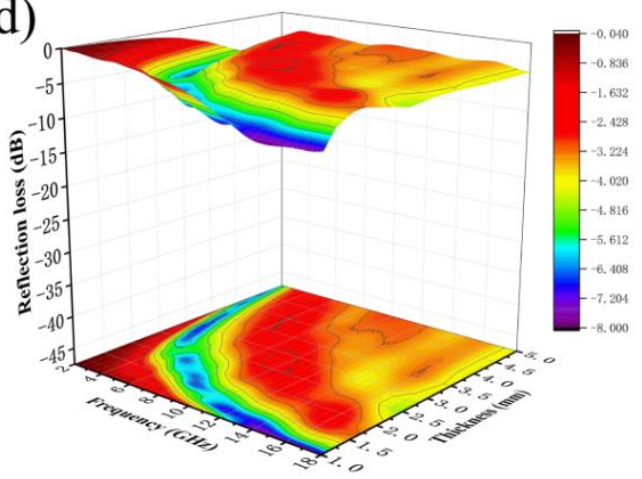

Fig. 7

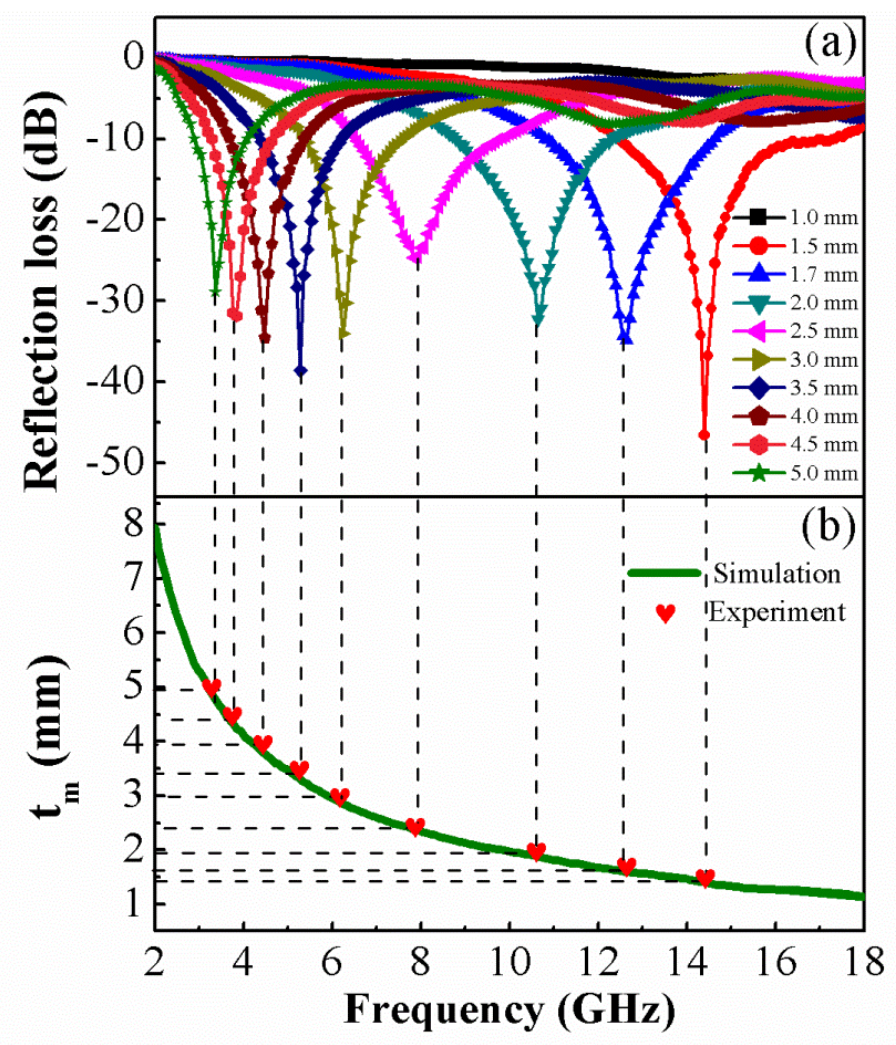

Fig. 8 


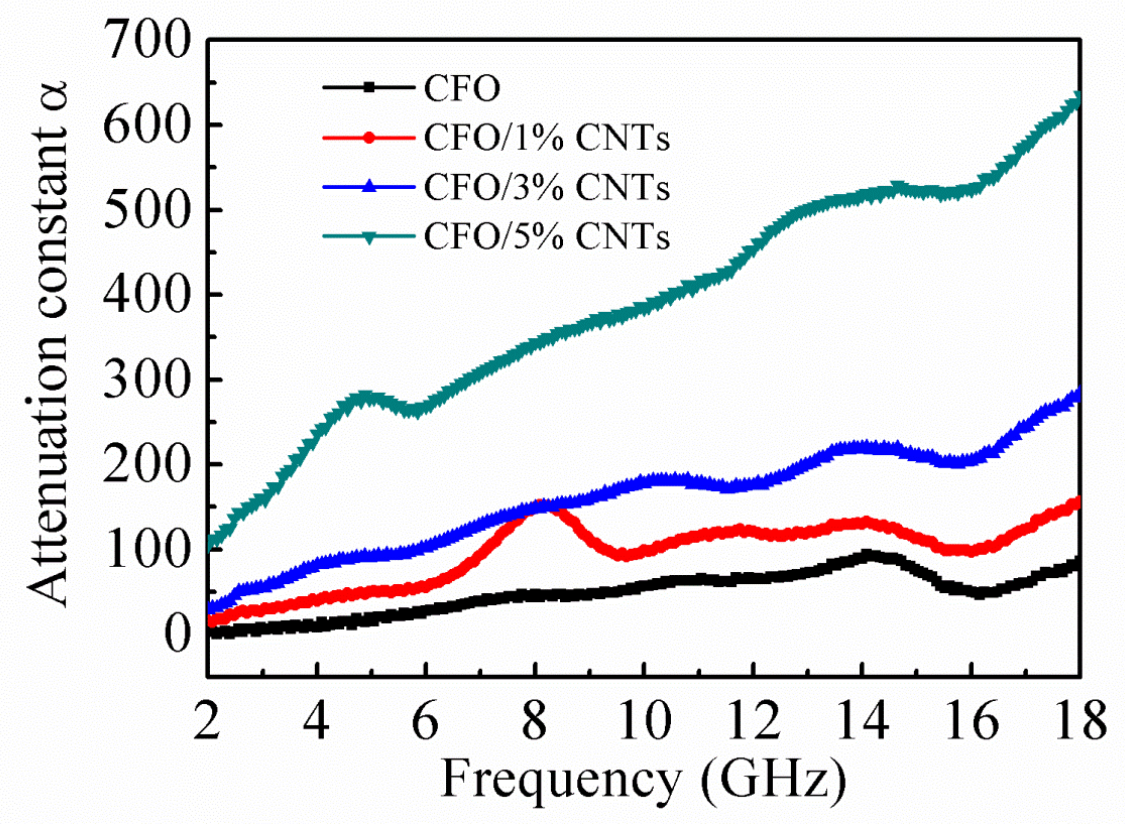

Fig. 9
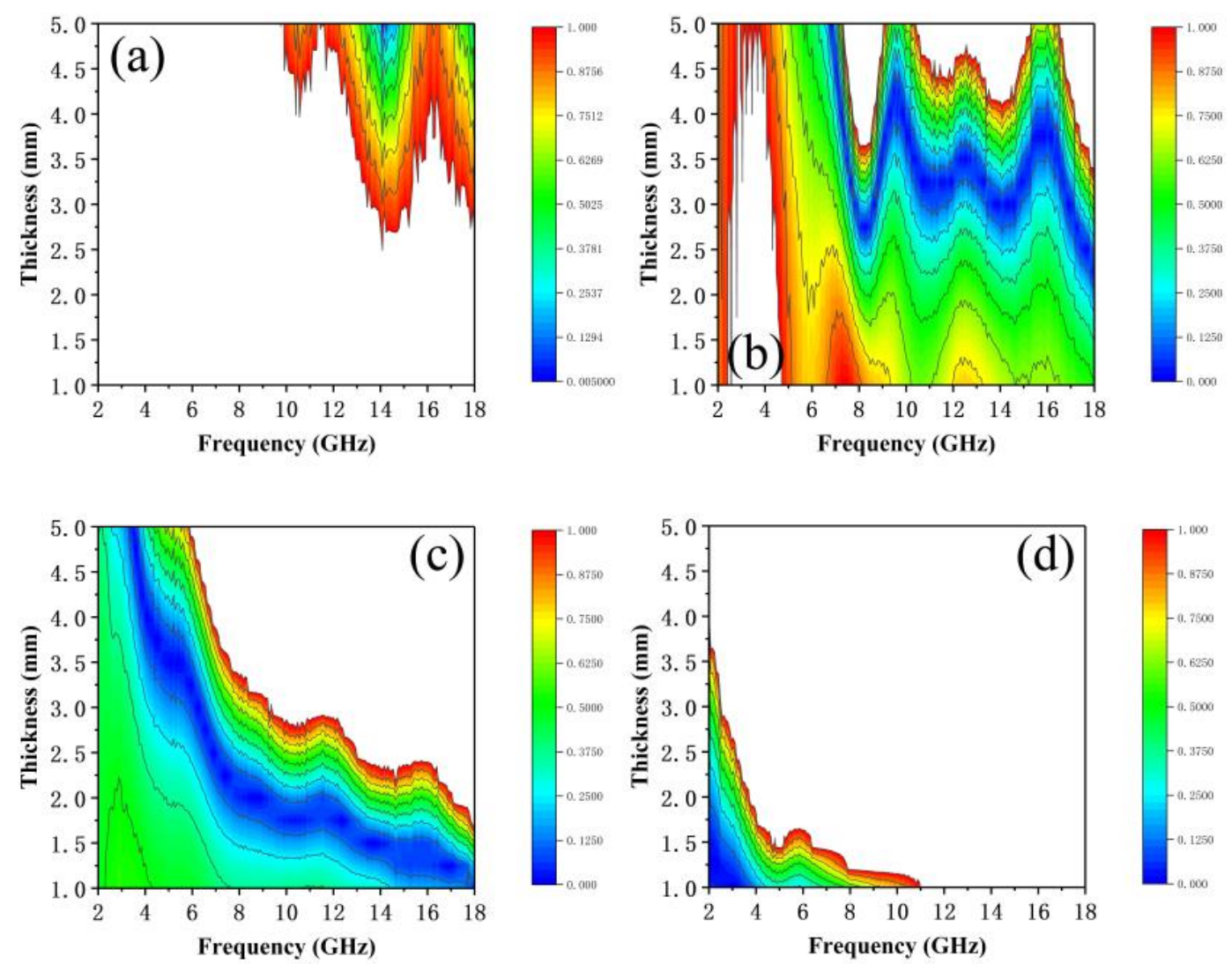

Fig. 10 
Figures

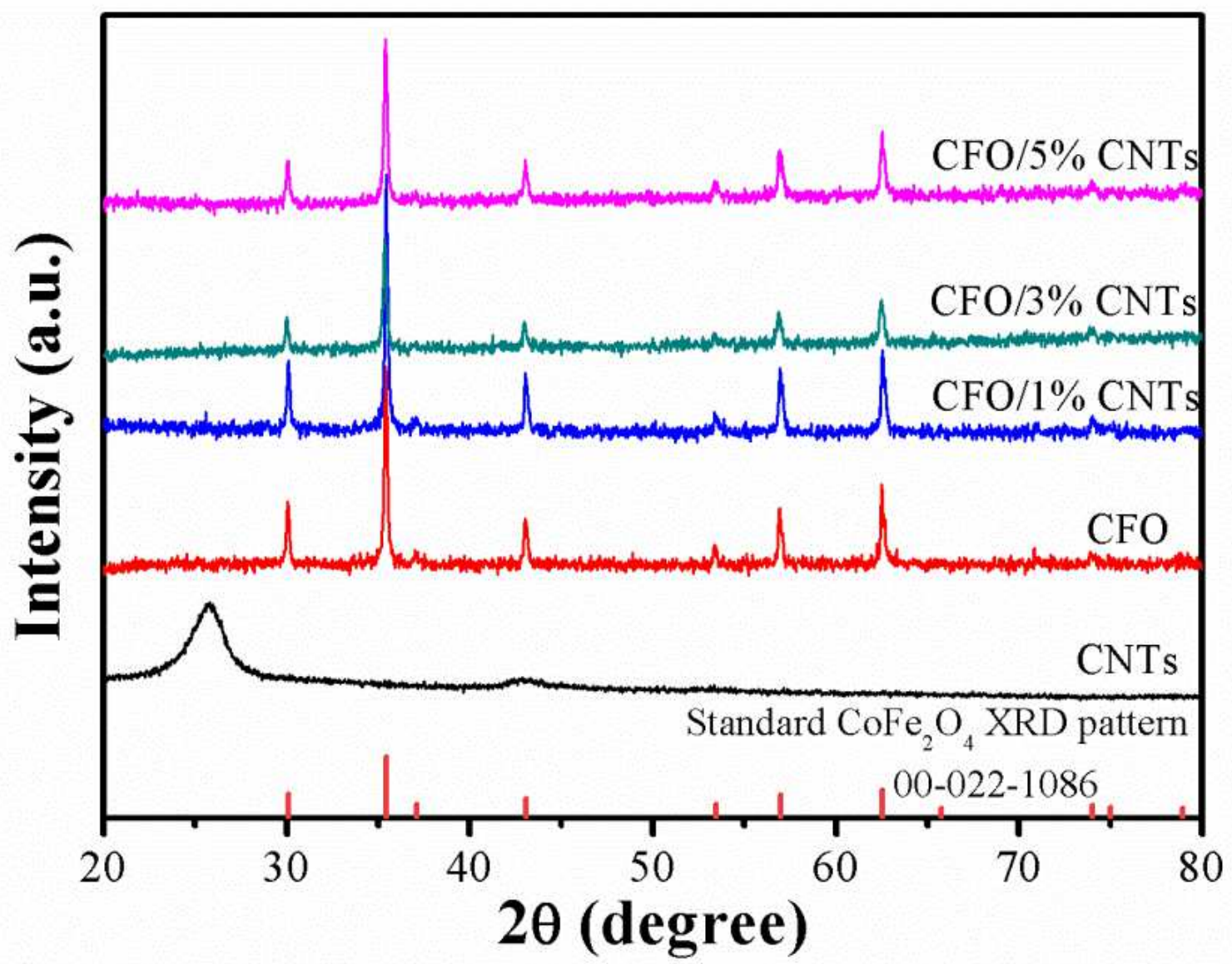

Figure 1

XRD patterns of as-obtained CoFe204/CNTs composites with various mass ratios. 


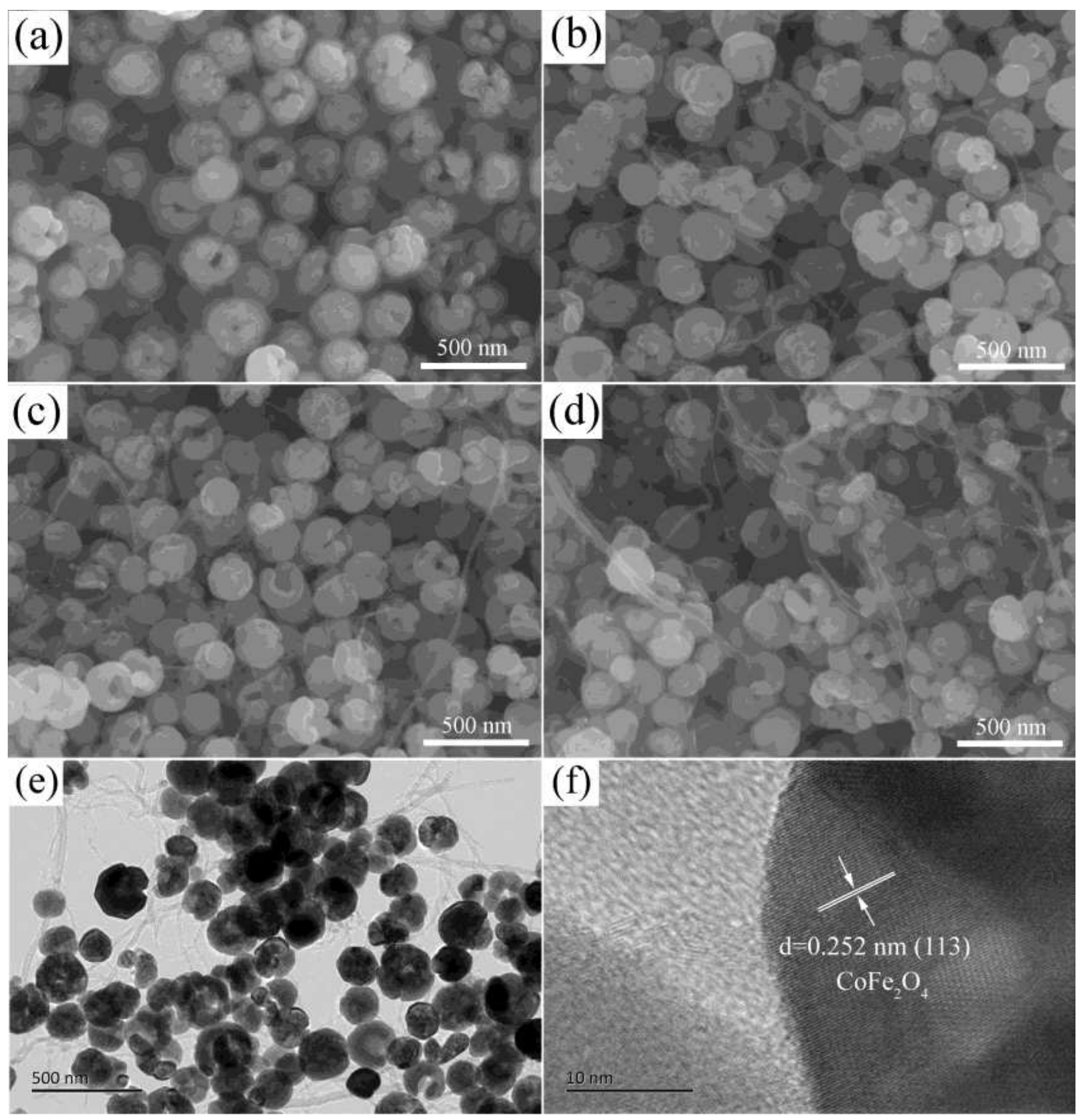

Figure 2

SEM image of the composites with CFO (a), CFO/1\% CNTs (b), CFO/3\% CNTs (c) and CFO/5\% CNTs (d). $(e, f)$ TEM images of CFO/3\% CNTs. 


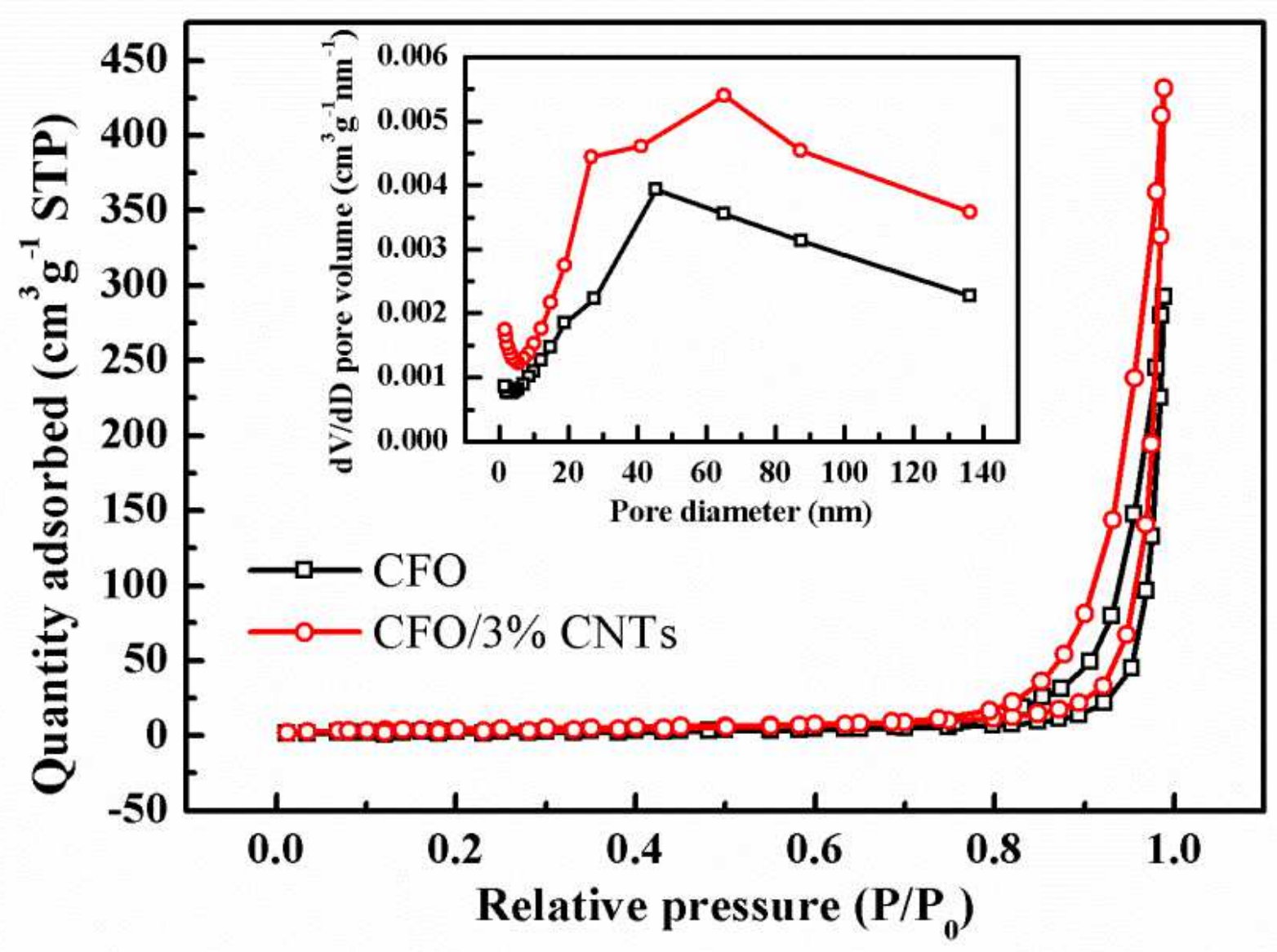

Figure 3

N2 adsorption-desorption isotherms of all as-prepared samples. The corresponding pore size distribution is shown in the insert. 

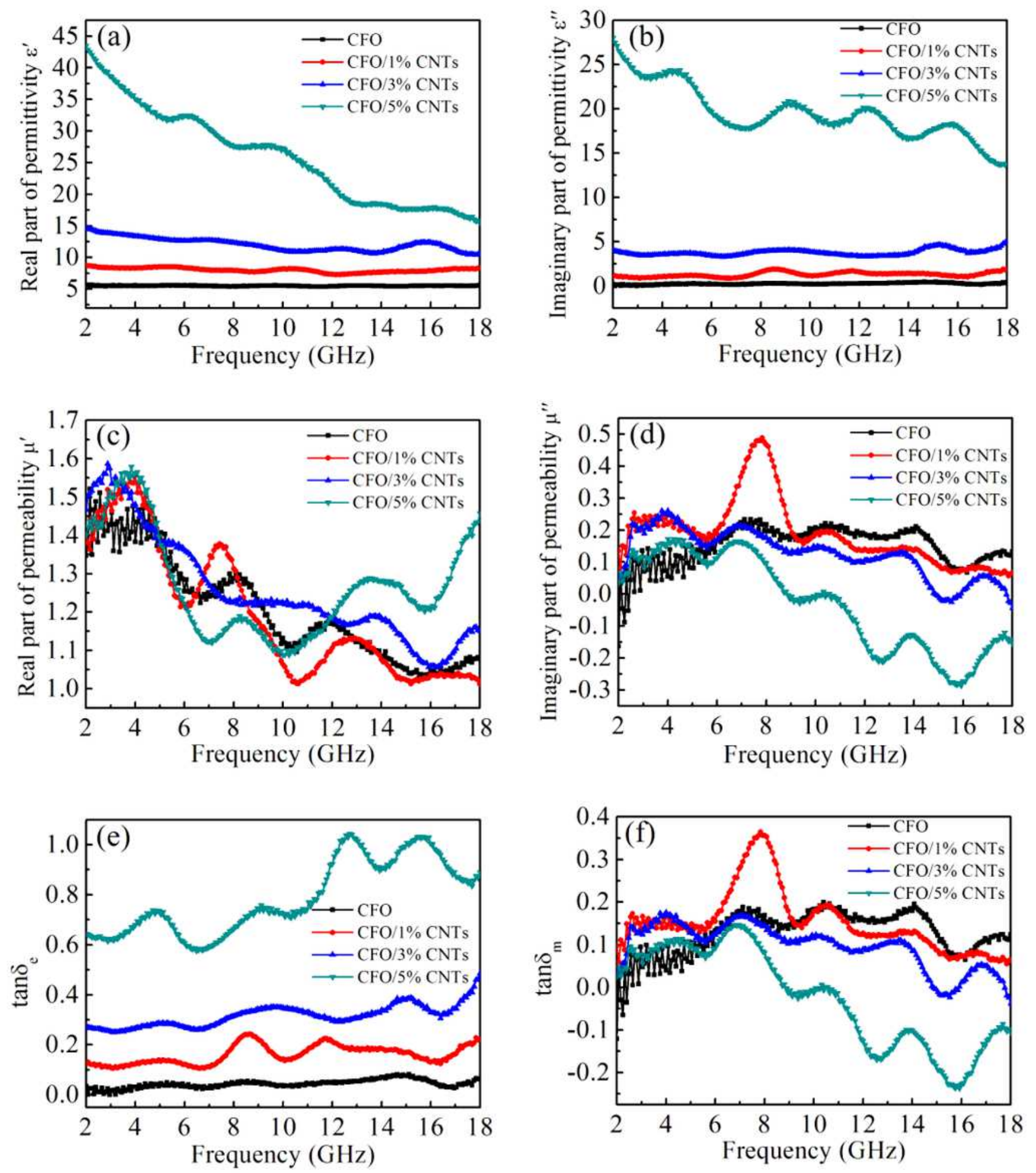

Figure 4

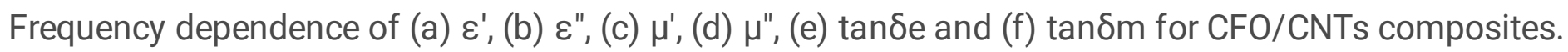




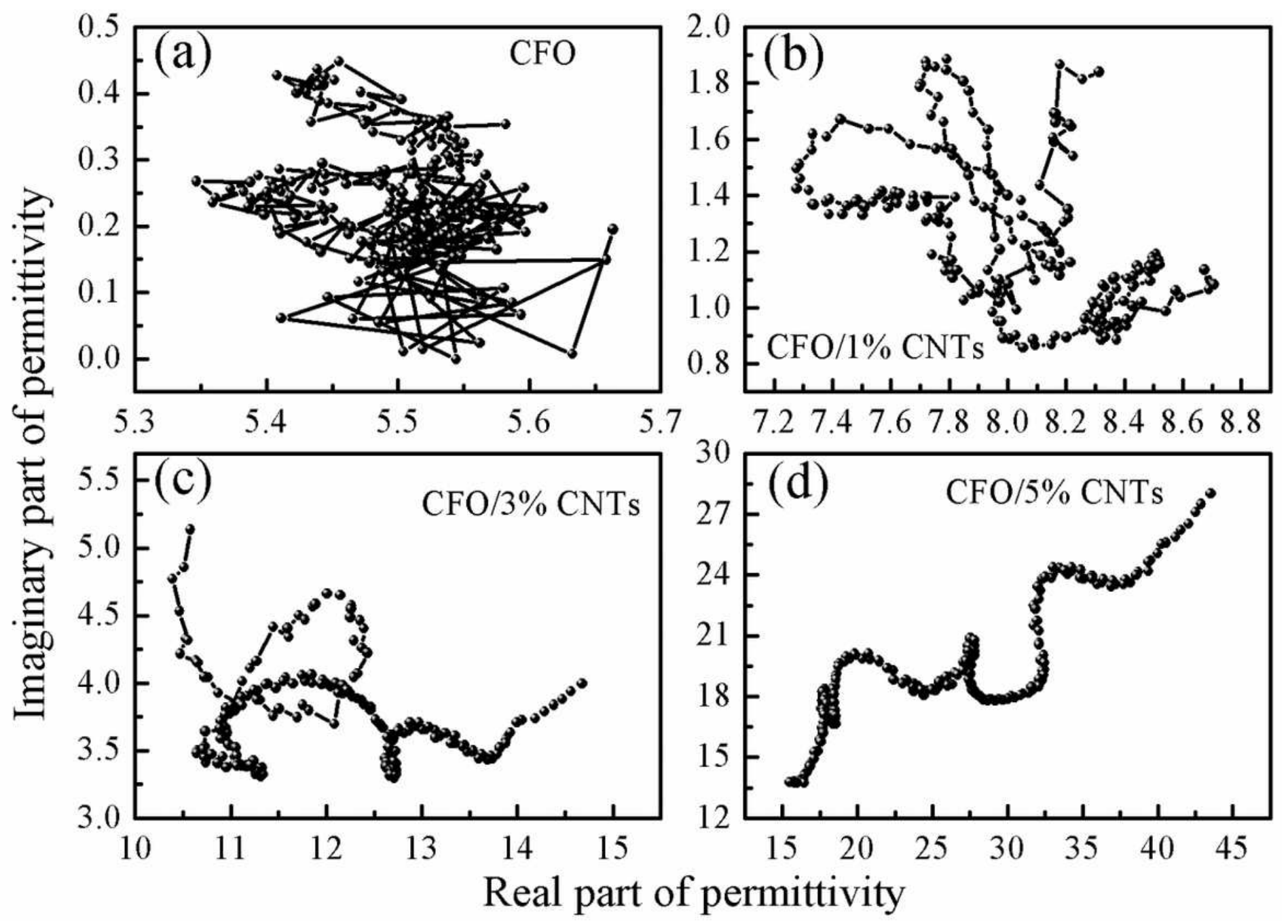

Figure 5

Typical Cole-Cole semicircle of composites with various load concentration of carbon nanotubes. 


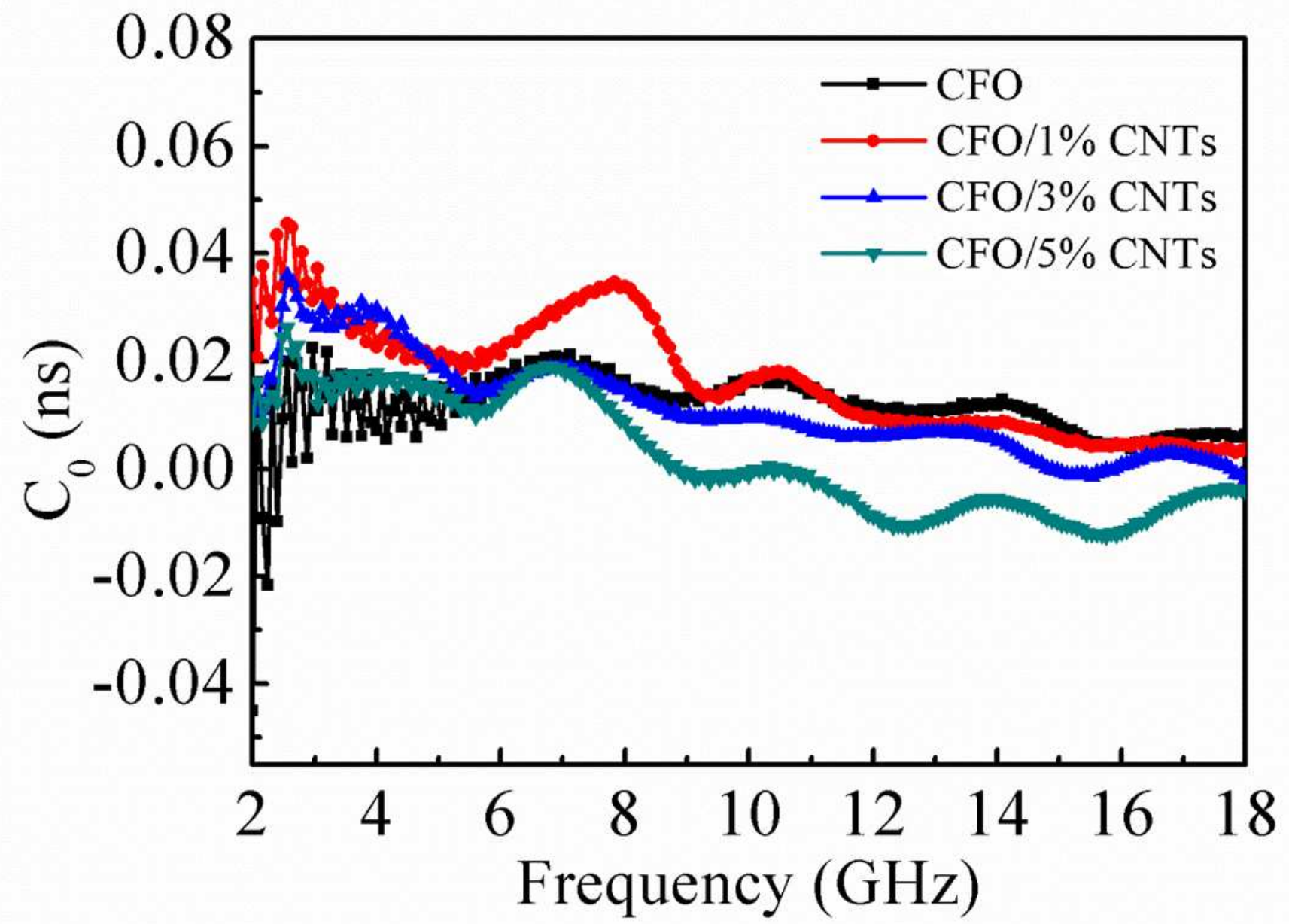

Figure 6

The $\mathrm{C} 0$ constant of eddy current loss versus frequency for all as-prepared samples. 
(a)

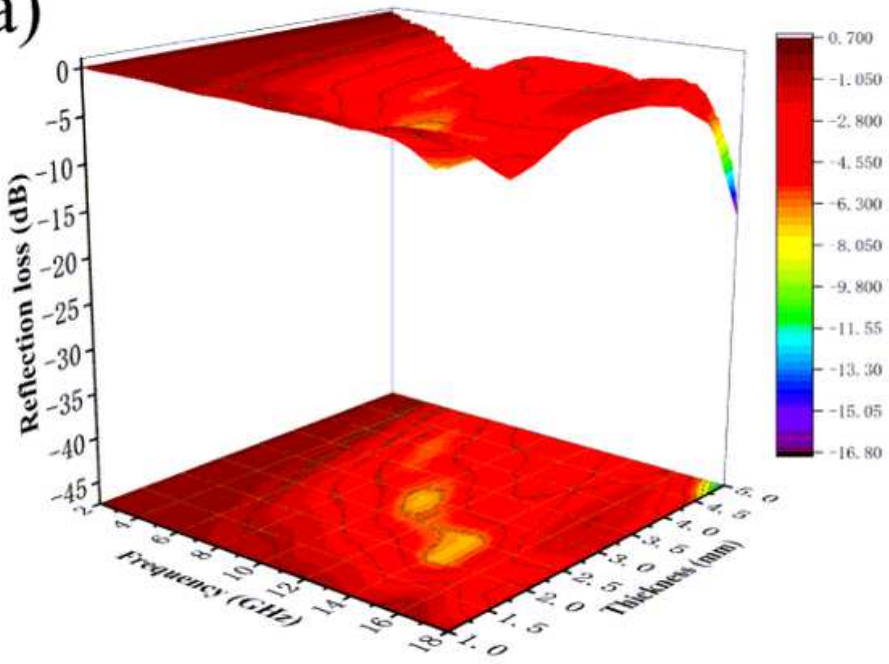

(c)

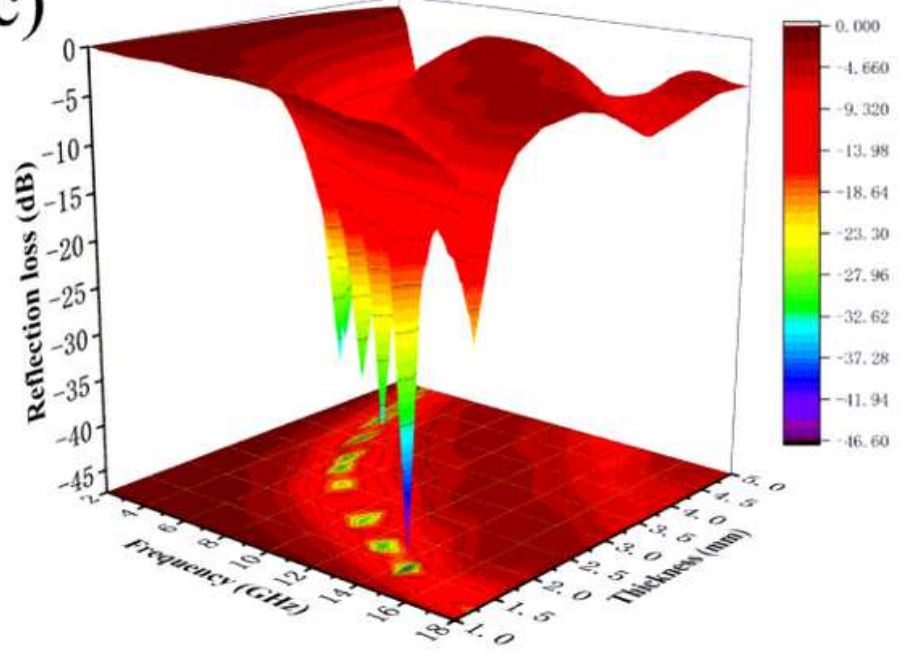

(b)

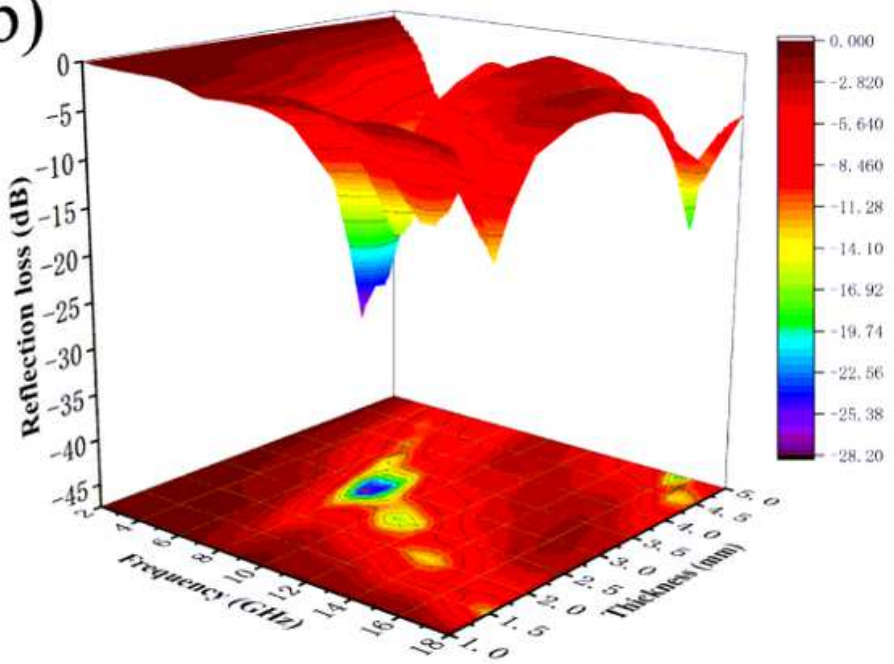

(d)

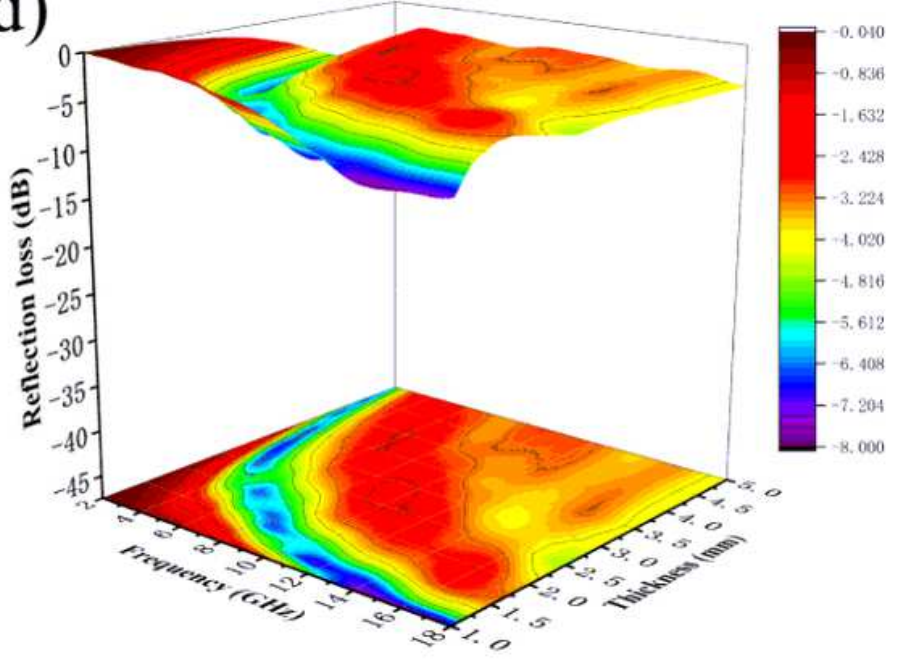

Figure 7

Three-dimensional reflection loss with different frequency and thickness for samples (a) CFO (a), (b) CFO/1\% CNTs, (c) CFO/3\% CNTs and (d) CFO/5\% CNTs . 


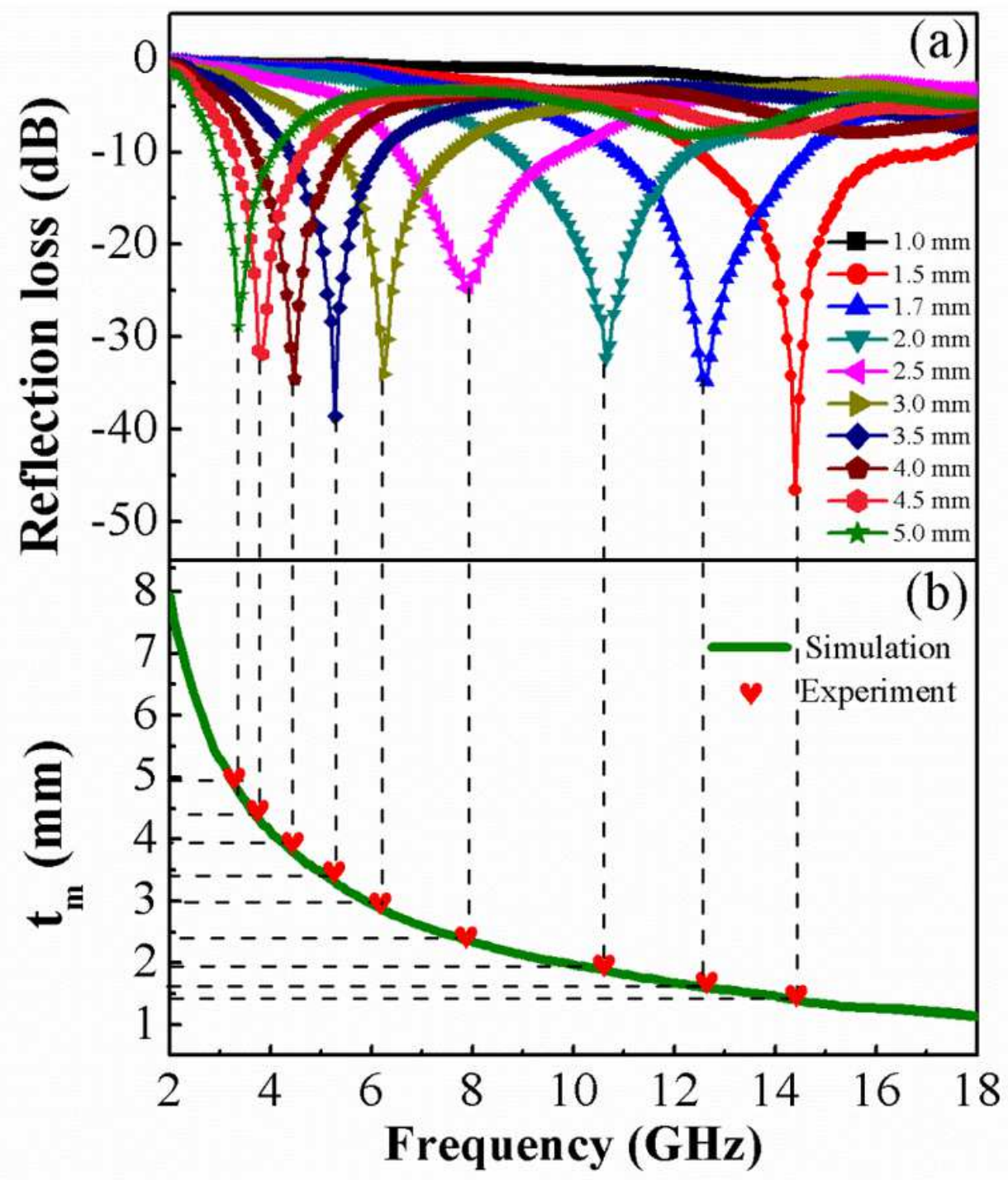

Figure 8

(a) Frequency dependence of reflection loss and (b) corresponding matching thickness versus frequency plots of $\mathrm{CFO} / 3 \% \mathrm{CNTs}$ under $\lambda / 4$ model (the red heart type represents experimental data and green line represents fitting plots). 


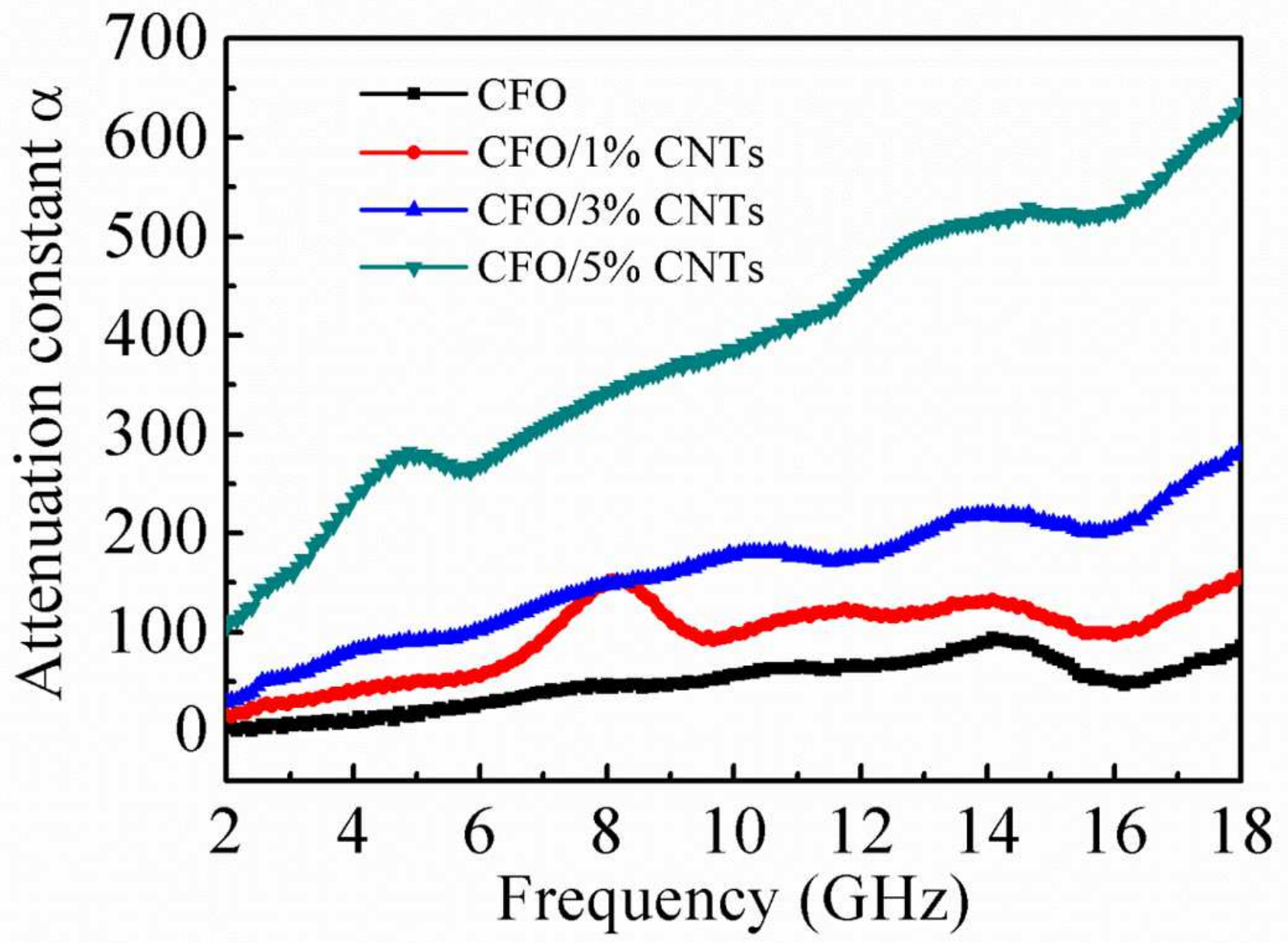

Figure 9

Frequency dependence of attenuation constant a of all as-prepared samples. 

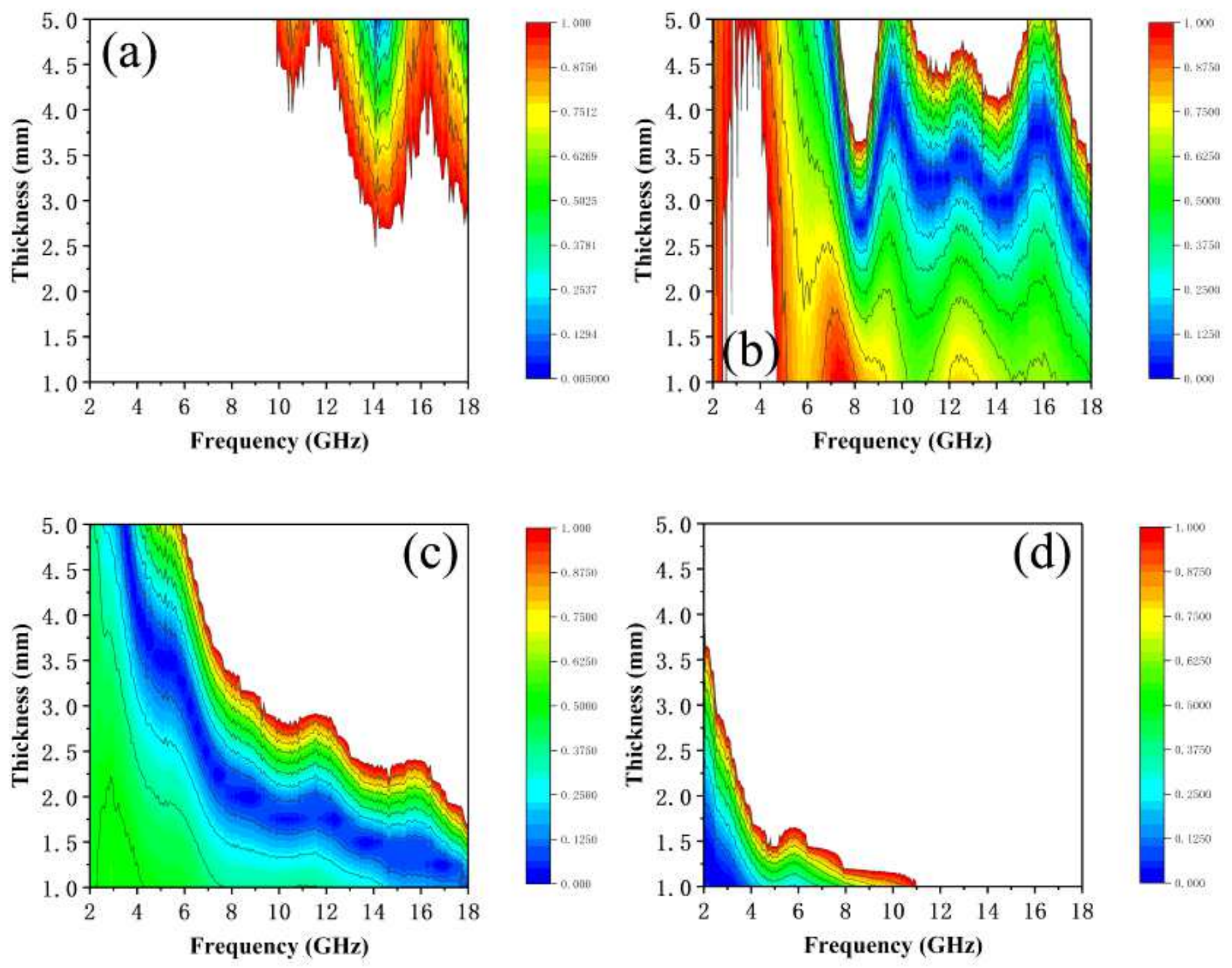

Figure 10

Calculated delta value maps for samples (a) CFO, (b) CFO/1\% CNTs, (c) CFO/3\% CNTs and (d) CFO/5\% CNTs with various absorber thicknesses in $2.0-18.0 \mathrm{GHz}$. 